\title{
Bimolecular and Unimolecular Contributions to the Disparate Self-Chemical Ionizations of $\alpha$-Pinene and Camphene Isomers
}

\author{
Touradj Solouki and Jan E. Szulejko \\ Chemistry Department, University of Maine, Orono, Maine, USA
}

\begin{abstract}
The contributions of molecular and fragment ions toward the disparate self-chemical ionization (SCI) of $\alpha$-pinene and camphene isomers were investigated. A kinetic model was constructed to predict the SCI outcomes for these two $\mathrm{C}_{10} \mathrm{H}_{16}$ isomers. A major portion of the camphene molecular ions (isolated $500 \mathrm{~ms}$ after the $10 \mathrm{~ms}$ EI event at $24 \mathrm{eV}$ ) unimolecularly dissociated within $200 \mathrm{~s}$ of the ionization event. Conversely, under similar experimental conditions, the $\alpha$-pinene molecular ions as well as the major fragment ions of $\alpha$-pinene and camphene showed no unimolecular dissociation. The $\alpha$-pinene and camphene molecular ions yielded product ions through two different reaction mechanisms (direct charge-transfer $\{C T\}$ and indirect proton transfer $\{\mathrm{PT}\}$ ). The isolated terpene fragment ions at $\mathrm{m} / \mathrm{z} 93$ and 121 reacted with their respective neutrals to produce $[\mathrm{M}+\mathrm{H}]^{+}$. Proton affinity (PA) bracketing experiments, PA additivity schemes, and alkene PA versus adiabatic ionization energy (IE) linear correlation indicated that the PAs of camphene and $\alpha$-pinene were comparable ( $\sim 210 \pm$ $2 \mathrm{kcal} \cdot \mathrm{mol}^{-1}$ ). The observed $[\mathrm{M}+\mathrm{H}]^{+} \mathrm{SCI}$ terpene ions were mainly the products of various fragment ion reactions. (J Am Soc Mass Spectrom 2007, 18, 2026-2039) (c) 2007 American Society for Mass Spectrometry
\end{abstract}

$\mathrm{P}$ reviously, we used a pre-concentrator gas chromatography Fourier transform ion cyclotron resonance PC/GC/FT-ICR) mass spectrometer for headspace analysis of detached pine twigs [1]. It was observed that the GC eluted camphene $\left(\mathrm{C}_{10} \mathrm{H}_{16}\right)$ underwent SCI whereas the other terpene isomers $\left(\mathrm{C}_{10} \mathrm{H}_{16}\right)$ did not show any significant SCI products. This was evidenced by a smaller $\mathrm{m} / \mathrm{z}$ 136:137 ratio $(\sim 1: 1)$ for camphene compared with other GC eluted terpene isomers (such as $\alpha$-pinene), which showed "normal" natural isotopic abundance ( 1:0.1). The variations in the observed SCI patterns for $\alpha$-pinene and camphene isomers sparked our interest to find the reasons for their different SCI propensities. The chemical structures of $\alpha$-pinene (1) and camphene (2) isomers $\left(\mathrm{C}_{10} \mathrm{H}_{16}\right)$ are shown below.

The ion-chemistry of monoterpenes has been studied by a number of experimental methods such as electron ionization $[2,3]$, varying the ion source temperature $[2,4]$, photoelectron spectroscopy [5-7], field ionization [8], collision-induced-dissociation [2, 9], surface-induceddissociation [2], isotope labeling [10, 11], metastable ion spectroscopy [11-13], and charge-stripping spectroscopy [14]. Thomas and Willhalm [15] recorded the electron impact mass spectra of 30 monoterpenes and proposed fragmentation mechanisms. The fragmenta-

Address reprint requests to Professor T. Solouki, Chemistry Department, University of Maine, 5706 Aubert Hall, Orono, ME 04469-5706, USA. E-mail: solouki@maine.edu tion mechanisms for terpene ions may involve extensive scrambling and rearrangements and therefore at best are tentative $[10,11]$.

Proton transfer reaction-mass spectrometry (PTRMS) has been proposed as a sensitive method to detect environmental terpene analytes (as protonated terpene species) [16-18]. Chemical ionization (CI) mass spectra of terpenes have been reported [18] but the SCI of terpenes has not been studied previously. We present the first detailed studies on the SCI of $\alpha$-pinene and camphene; here, SCI is referred to the formation of $[\mathrm{M}+\mathrm{H}]^{+}$by reaction of either its fragment or $\mathrm{M}^{+}$ions with neutral parent molecules (M).

Series of experiments were designed to answer the following questions: (1) What are the key chemical processes that give rise to different SCI patterns for $\alpha$-pinene and camphene isomers? (2) Can we use our experimental findings and construct a simple kinetic model to predict SCI mass spectral patterns as a function of time and pressure?

In an SCI experiment, a given neutral analyte may react with its molecular $\left(\mathrm{M}^{+}\right)$and various fragment $\left(\mathrm{f}_{\mathrm{i}}^{+}\right)$ ions to yield $[\mathrm{M}+\mathrm{H}]^{+}$. Hence, to answer the aforementioned questions (1) and (2), we investigated the SCI contributions from terpene molecular ions and various major fragment ions. Results from three research areas that include i- unimolecular dissociation of parent and fragment ions, ii- reactivities of major fragment ions, and iii- PA of $\alpha$-pinene and camphene, are reported. 

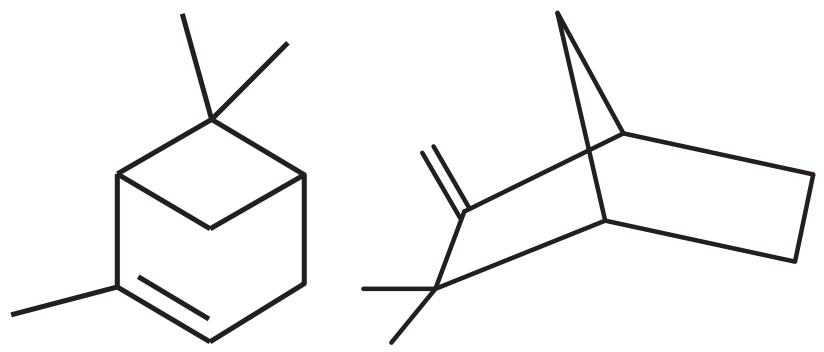

$\alpha$-Pinene 1

\section{Camphene 2}

Details on the use of kinetic data to predict SCI mass spectral appearances are presented.

\section{Experimental}

\section{Instrumentation}

All experiments were performed on a 7-T FT-ICR mass spectrometer (IonSpec Corporation, Forest Lake, CA) in the internal ion generation mode [19]. The previous GC/FT-ICR MS studies were performed at $24 \mathrm{eV}$ electron energy to eliminate ionization of the helium carrier gas [1]. Hence, we used the same $24 \mathrm{eV}$ ionization energy for the bulk of the studies described herein. The stored waveform inverse Fourier transform (SWIFT) [20] was used to isolate the ions of interest. The isolated ions were allowed to react either unimolecularly or with chemical reagents, using the representative event sequences shown schematically in Figure 1. Additional details on specific experiments are given in the text. In some experiments, supplementary pulsed valve (PV) and ion isolation events were used for SCI and ion cooling (not shown in Figure 1).

\section{Chemicals and Sample Preparation}

The terpenes and chemical reagents were purchased from Aldrich Chemical Company, Inc. (Milwaukee, WI) and used without further purification except for conventional freeze-thaw degassing procedure on the sample introduction system. Analytes were introduced into the ICR cell through the pulsed and/or pulsed-leak [21] valve (PLV) sample introduction systems.

\section{ICR Cell Pressure Geometry Factor Determination}

Analyte pressures were measured by a remote GranvillePhilips series 274 (Granville-Phillips, Boulder, CO) Bayard-Alpert type ionization gauge tube (located $\sim 1$ $\mathrm{m}$ from the ICR cell) and corrected for their relative ion gauge chemical sensitivity (CS) [22, 23]. Estimated [24] and literature reported molecular polarizabilities (MP) [25] were used to correct ion gauge pressure readings based on an MP versus CS correlation scheme [22]. In addition, a cell pressure geometry factor (gf) was ap- plied to estimate the actual analyte pressure in the ICR cell. Here, gf is defined as (chemical sensitivity corrected ion gauge pressure reading)/(actual ICR cell pressure). The experiments to determine gf were conducted under similar experimental conditions as those used for terpene ion-molecule reactions (i.e., the EI filament was on $>3 \mathrm{~h}$ ).

Bimolecular rate constant for the $\mathrm{PT}$ reaction from $\mathrm{CH}_{3} \mathrm{CO}^{+}$to acetone $\left(\mathrm{CH}_{3} \mathrm{CO}^{+}\{\mathrm{m} / \mathrm{z} 43\}+\mathrm{C}_{3} \mathrm{H}_{6} \mathrm{O} \rightarrow\right.$ $\left.\mathrm{CH}_{2} \mathrm{CO}+\mathrm{C}_{3} \mathrm{H}_{7} \mathrm{O}^{+}\{\mathrm{m} / \mathrm{z} 59\}\right)$ was chosen to determine the ICR cell pressure geometry factor. An averaged ICR literature PT reaction rate of $2.7 \times 10^{-10} \mathrm{~cm}^{3} \cdot \mathrm{molec}^{-1}$ $\cdot \mathrm{s}^{-1}[26]$ and an ion gauge sensitivity factor of 2.5 [22] for acetone were used to determine the present gf of 0.55 for our instrument. All bimolecular rate constants determined in this work have been scaled using a gf $=$ 0.55 . The temperature of acetone and other neutral reagents in the ICR cell was nominally taken as $\sim 296$ $( \pm 1) \mathrm{K}$, the measured ambient laboratory temperature; all ion-molecule reactions were carried out under similar ICR cell temperature conditions used in the determination of gf.

\section{Data Analysis and Kinetic Schemes}

The ion abundance data from IonSpec software output were normalized to one for each reaction delay time and analyzed using pseudo first (Scheme 1) and irreversible two-step (pseudo) first-order consecutive decay reaction

(a)

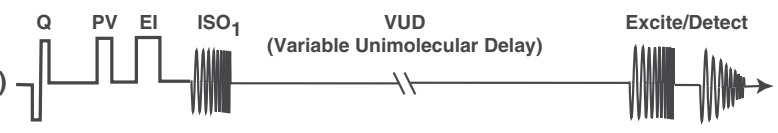

(b)

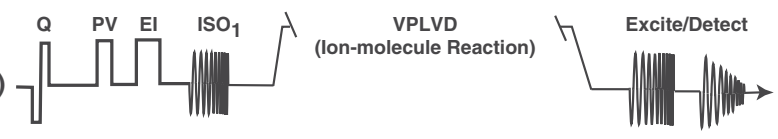

(c)

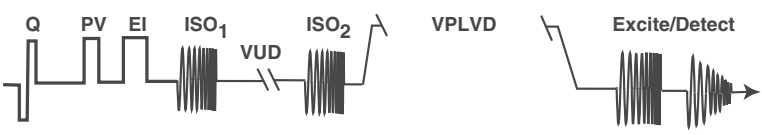

(d)

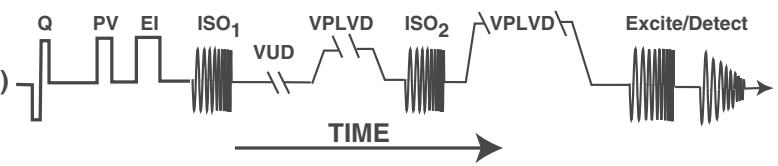

Figure 1. Experimental event sequences. Common events for (a), (b), (c), and (d) type of experiments included; Q: ion removal (Quench), PV: pulsed valve sample introduction at 0 to $3 \mathrm{~ms}$, EI: 5 $\mathrm{ms} 24 \mathrm{eV}$ electron impact starting at $995 \mathrm{~ms}, \mathrm{ISO}_{1}$ : SWIFT isolation ending at $1450 \mathrm{~ms}$ unless otherwise specified in text. In some experiments, additional events were added after the $\mathrm{ISO}_{1}$. For example, ion-molecule neutral reactants were admitted into the ICR cell using a variable pulsed leak valve and variable ionmolecule reaction delay (VPLVD) event. Additional details for (a) to (d) types of experiments include (a): variable unimolecular reaction delay (VUD) up to $2000 \mathrm{~s}$ for BIRD type experiments, (b): variable ion-molecule reaction delay up to $2000 \mathrm{~s}$, (c): variable unimolecular reaction delay after first isolation $\left(\mathrm{ISO}_{1}\right)$, followed by re-isolation $\left(\mathrm{ISO}_{2}\right)$ and variable ion-molecule reaction delay, (d): combined VUD and VPLVD after the first isolation $\left(\mathrm{ISO}_{1}\right)$, followed by re-isolation $\left(\mathrm{ISO}_{2}\right)$ and a second VPLVD. 
(Scheme 2) kinetic schemes. The curve-fitting results from Origin 7.0 software (OriginLab Corporation, Northampton, MA) were used to determine the unimolecular and/or bimolecular rate constants $\left(k_{x}\right)$ as well as the reactive population fractions and reaction branching ratios $\left(R_{x}\right)$.

$$
\mathrm{A}^{+}+\mathrm{B} \rightarrow \mathrm{P}_{1}^{+}+\mathrm{C}
$$

\section{Scheme 1}

$$
\begin{aligned}
& {\left[\mathrm{A}^{+}\right]=\left[\mathrm{A}_{\mathrm{ur}}^{+}\right]+\left[\mathrm{A}_{\mathrm{r}}^{+}\right]_{0} \times \exp \left(-\mathrm{t} / \tau_{1}\right)} \\
& {\left[\mathrm{P}_{\mathrm{i}}^{+}\right]=\mathrm{R}_{\mathrm{i} \cdot} \cdot\left[\mathrm{A}_{\mathrm{r}}^{+}\right]_{0} \times\left(1-\exp \left(-\mathrm{t} / \tau_{\mathrm{i}}\right)\right)}
\end{aligned}
$$

where $\left[\mathrm{A}^{+}\right]$is the abundance of the $\mathrm{A}^{+}$ions at a given reaction delay time $t(\mathrm{~s}),\left[\mathrm{A}_{\mathrm{ur}}^{+}\right]$is the unreactive component of the $\mathrm{A}^{+}$ions, $\left[\mathrm{A}_{\mathrm{r}}^{+}\right]_{0}$ is the initial concentration of the reactive fraction of $\mathrm{A}^{+}$at the end of the last ion isolation event (e.g., end of $\mathrm{ISO}_{1}$ and $\mathrm{ISO}_{2}$ in Figure $1 \mathrm{a}-\mathrm{b}$ and $1 \mathrm{c}-\mathrm{d}$, respectively), $\tau_{1}$ is the pseudo firstorder time constant, B is either the reactant neutral compound or ambient photons for a blackbody infrared radiative dissociation (BIRD) type reaction, and $C$ is (are) the neutral product(s). The product ion profiles were analyzed using eq $1 b$, where $R_{i}$ and $\tau_{i}$ are the reaction branching ratio and time constant for the $i^{\text {th }}$ competing product channel, respectively.

$$
\left[\mathrm{A}^{+}\right] \stackrel{\mathrm{k}_{1}}{\rightarrow}\left[\mathrm{P}_{1}^{+}\right] \stackrel{\mathrm{k}_{2}}{\rightarrow}\left[\mathrm{P}_{2}^{+}\right]
$$

\section{Scheme 2}

$$
\begin{aligned}
& {\left[\mathrm{P}_{1}^{+}\right]=\left(\tau_{2} /\left(\tau_{1}-\tau_{2}\right)\right) \times\left[\mathrm{A}_{\mathrm{r}}^{+}\right]_{0} \times\left(\exp \left(-\mathrm{t} / \tau_{1}\right)\right.} \\
& \left.-\exp \left(-\mathrm{t} / \tau_{2}\right)\right)
\end{aligned}
$$

For the reactions reported here, we assumed that the intermediate species $\left(\mathrm{P}_{1}^{+}\right)$had no unreactive components. This is a reasonable assumption because all intermediate product ions reacted away in the experiments reported herein. The Origin 7 curve fitting correlation coefficients for Scheme 2 type reactions were all $\geq 0.95$. Derivation of a two-step consecutive reaction (eq 2) is given in reference [27].

Equation 2 is valid for the initial condition $\left[\mathrm{P}_{1}^{+}\right]=0$ at $\mathrm{t}=0 \mathrm{~s}$. The zero reaction delay time $(\mathrm{t}=0 \mathrm{~s})$ corresponds to the end of the last ion isolation events in Figure 1 and not the ionization event. Using eqs $1 \mathrm{a}$ and 2 , the unknown parameters $\tau_{1}$ and $\tau_{2}$ in a two-step ion-molecule reaction can be obtained. To extract the unknown parameters via curve fitting of eq 2, the following steps were employed:

Step 1: Use eq 1 and kinetic plots to find $\tau_{1}$ and $\left[\mathrm{A}_{\mathrm{r}}^{+}\right]_{0}$.

Step 2: Substitute $\tau_{1}$ and/or $\left[\mathrm{A}_{\mathrm{r}}^{+}\right]_{0}$ into eq 2 as constraints, and find $\tau_{2}$. The curve fitting kinetic results were examined to ensure consistency with physical reality, e.g., $\left[\mathrm{A}_{\mathrm{r}}^{+}\right]_{0}+\left[\mathrm{A}_{\mathrm{ur}}^{+}\right]=1.0$ and both $\left[\mathrm{A}_{\mathrm{r}}^{+}\right]_{0}$ and $\left[\mathrm{A}_{\mathrm{ur}}^{+}\right]$ should be within the range 0 to 1.0 .

The bimolecular rate constants were calculated using the relationship between the time constants $\left(\tau_{\mathrm{m}}\right)$ and neutral number density [N]:

$$
\mathrm{k}=1 /\left([\mathrm{N}] \cdot \tau_{\mathrm{m}}\right)
$$

where $[\mathrm{N}]$ is the number density of the reactant neutral in the FT-ICR cell (in molecules $\mathrm{cm}^{-3}$ ) and $\mathrm{m}=1,2$, or $\mathrm{i}$. The neutral reactant pressure in the FT-ICR cell was calculated by applying the appropriate ion gauge chemical sensitivity and cell pressure geometry correction factors. The number densities ([N]) were calculated using standard ideal gas equations and using the corrected values for analyte pressure. The experimental bimolecular rate constants are reported with an estimated precision of $\pm 10 \%$.

\section{Results and Discussion}

Only representative ion-molecule and/or unimolecular decay reactions are included in Table 1 but the results from additional reactions are discussed in the text.

A summary of the kinetic data is organized in Table 1 to guide the relevant discussions. For example, the unimolecular dissociation of camphene molecular ions (Reactions 1, 2, Table 1) was studied to determine reactive component life times. Ion-molecule reactions of parent terpene ions were investigated to determine reactive components and reaction rate constants for CT and PT reactions (Reactions $3-5$, Table 1 ). To estimate the IE of camphene, (listed in the NIST database as $<8.55 \mathrm{eV}$ ) unimolecularly cooled $m$-xylene $\mathrm{M}^{+}$was reacted with camphene neutrals (Reactions 6, 7, Table 1).

Major terpene fragment ions (species at $m / z 93$ and 121) were SWIFT isolated and their CT and PT kinetics were followed (Reactions 8-16, Table 1) to determine their SCI contributions. Bracketing experiments were utilized to estimate PAs (Reactions 17-22, Table 1); PAs of the parent terpenes and conjugate bases of their fragment ions influence the kinetics of PT in SCI. PT reactions between SWIFT isolated (isotopically tagged) protonated $\alpha$-pinene and camphene at $m / z 138$ (i.e., the ${ }^{13} \mathrm{C}_{1}$ isotopomer of $\left.\left.[\mathrm{M}+\mathrm{H}]\right]^{+}\right)$with their neutral molecules were studied to compare PAs and reaction kinetics of these two terpene isomers (Reactions 23-25 in Table 1).

\section{Unimolecular and Bimolecular Reactions of Terpene Ions}

Ions not undergoing unimolecular decay. The unimolecular reactions of camphene were investigated using experimental event sequences of the type shown in Figure 1a. The SWIFT isolated molecular ions of $\alpha$-pinene did not show any measurable unimolecular dissociation prod- 


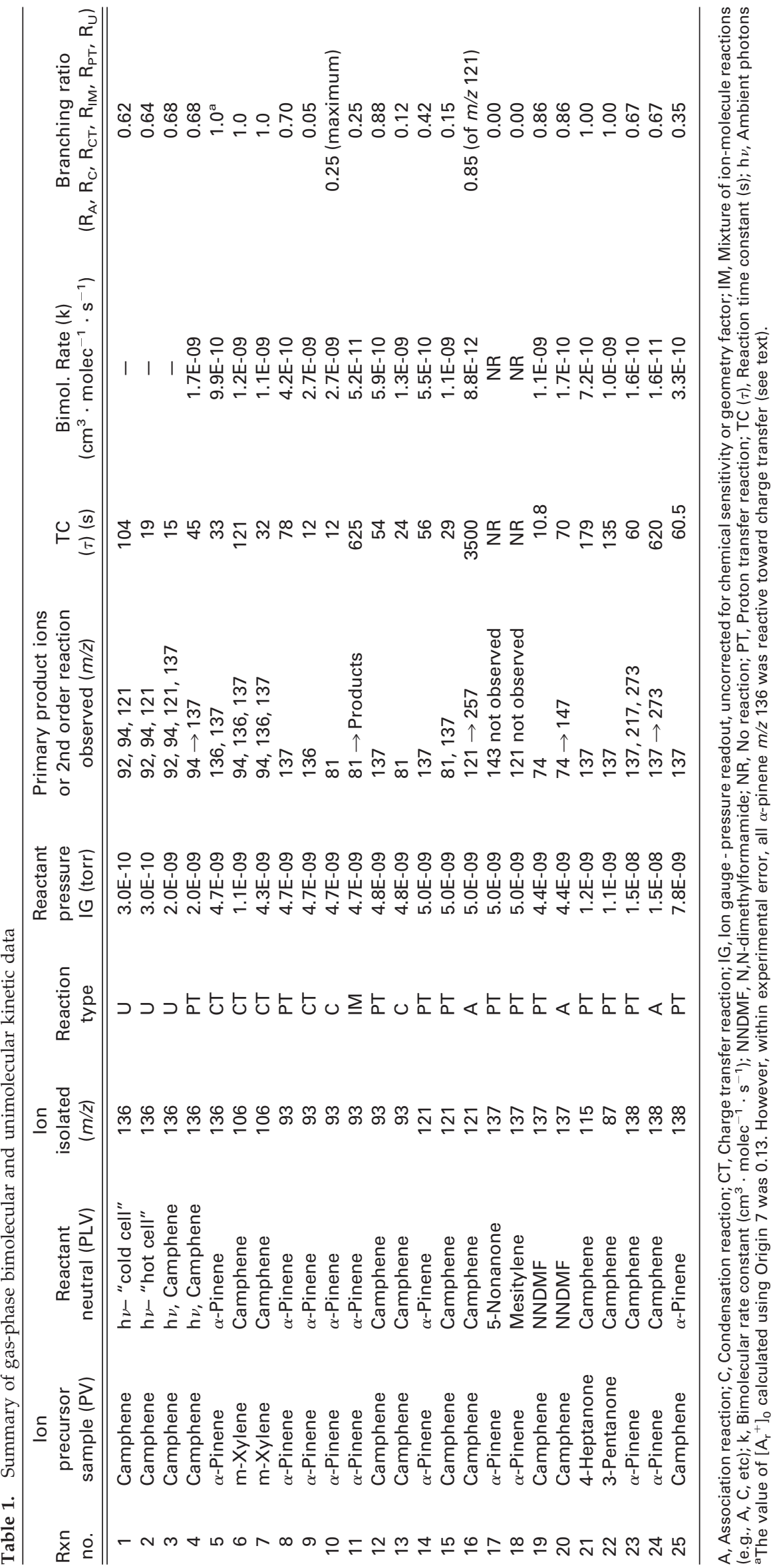


uctions up to $2000 \mathrm{~s}$ reaction delay. Also, SWIFT isolated fragment ions of both $\alpha$-pinene and camphene at $\mathrm{m} / \mathrm{z} 93$ and 121 did not show any measurable unimolecular reactivity. The unimolecularly dissociating fraction of any molecular ion population should be largest when the time delay between the EI and SWIFT isolation events is the shortest (i.e., before the ions have a chance to dissociate appreciably). Unlike the isolated camphene molecular ions, even at the shortest SWIFT isolation delay time of 500 ms (after the ionization event), no unimolecular dissociation products were observed for $\alpha$-pinene molecular ions for up to $2000 \mathrm{~s}$ reaction delay.

Ions undergoing unimolecular decay. The molecular ions of camphene, $\mathrm{M}_{\mathrm{ca}}^{-+}$, fragmented unimolecularly up to $\sim 400 \mathrm{~s}$ after the $10 \mathrm{~ms} 24 \mathrm{eV}$ electron impact event (shown in Figure 2 and summarized in Table 1, Reactions 1,2). The unimolecular reactions were monitored at the base pressure of $\sim 3 \times 10^{-10}$ torr. The main unimolecular dissociation channel for $\mathrm{M}_{\text {ca }}^{+}$ (-) was the loss of $\mathrm{C}_{3} \mathrm{H}_{6}$ to yield an ion at $\mathrm{m} / \mathrm{z}$ of 94 $(\square$, in Figure 2); minor channels included the formation of the ions at $m / z 92$ and $121(\triangle$, shown as summed up values in Figure 2).

Initially we noted that the unimolecular dissociation time constant $(\tau)$ for camphene $\left(\mathrm{M}_{\mathrm{ca}}^{+*} \mathrm{~m} / \mathrm{z} 136\right)$ varied from experiment to experiment, ranging from $\sim 15 \mathrm{~s}$ ("hot cell," EI filament on for more than $6 \mathrm{~h}$ ) to $\sim 120 \mathrm{~s}$ ("cold cell," EI filament turned off for $\sim 24 \mathrm{~h}$ before acquiring data). After conducting additional control experiments (Reactions 1 \{"cold cell"\} and 2 \{"hot cell"\} in Table 1), it became evident that the variations in $\tau$ were due to EI filament heating, in accord with a BIRD mechanism. The "cold" and "hot" ICR cell temporal plots are shown in Figure 2a and b, respectively. Ions at $\mathrm{m} / \mathrm{z} 136$ were SWIFT isolated $0.6 \mathrm{~s}$ after the end of the 10 $\mathrm{ms}$ ionization event.

In separate experiments (data not shown), the time delay between the EI and SWIFT isolation events was varied $(0.6 \mathrm{~s}$ to $50 \mathrm{~s}$ ) for the isolation of camphene $\mathrm{m} / \mathrm{z}$ 136. Extrapolating the $m / z 136$ decay curve back to the time of the EI event (using eq 1a in Origin 7) showed that the unimolecularly dissociating fraction $(\sim 0.65 \pm$ 0.03 ) of the total camphene $\mathrm{m} / \mathrm{z} 136$ population (at the time of the EI event) was independent of the ICR cell heating by the EI filament (within experimental error). These results suggest that there is no significant unimolecular isomerization or relaxation of the unimolecularly reactive camphene $\mathrm{m} / \mathrm{z} 136$ population to a unimolecularly nondissociating population (or vice versa).

SCI reactions of $\alpha$-pinene and camphene molecular radical cations. The reaction of SWIFT isolated $\alpha$-pinene radical cation, $\mathrm{M}_{\mathrm{ap}}^{+}$, with $\alpha$-pinene (Reaction 5, Table 1) yielded $\mathrm{m} / \mathrm{z} 137$ product ions and Origin 7 curve fitting gave a $\left[\mathrm{A}_{\mathrm{r}}^{+}\right]_{0}$ value of 0.13 . This suggests that $\mathrm{M}_{\mathrm{ap}}^{+}$ underwent a CT reaction with $\alpha$-pinene neutrals to re-establish the carbon isotopic natural abundance and yield the ${ }^{13} \mathrm{C}_{1}$ isotopomer of $\mathrm{M}_{\mathrm{ap}}^{+}(\sim 11 \%$ natural isotopic
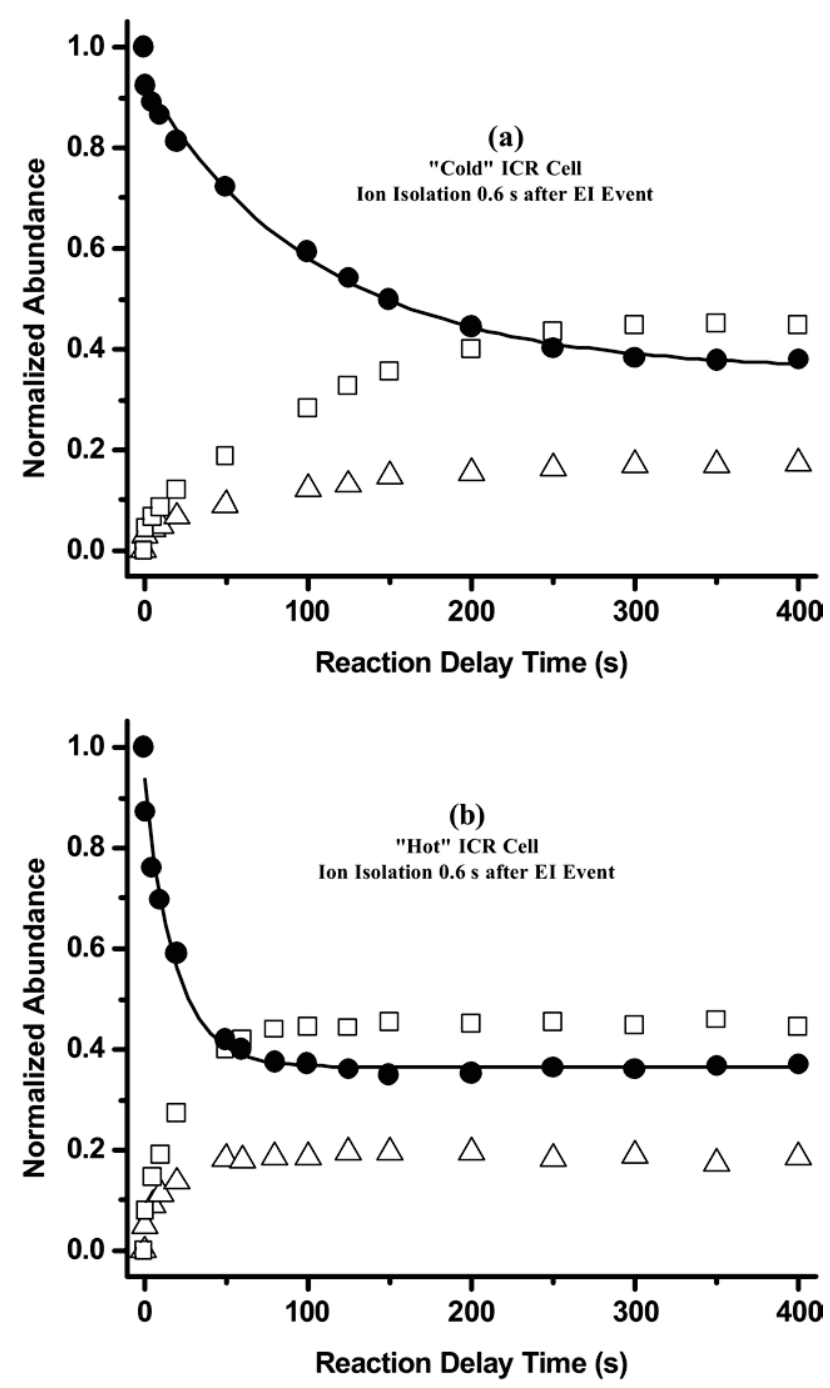

Figure 2. Temporal plots for unimolecular decay of camphene molecular ions at $\mathrm{m} / \mathrm{z} 136(\mathbf{0})$ : SWIFT isolated (a) $0.6 \mathrm{~s}$ after electron impact ionization event at room-temperature (i.e., ICR cell heating by the EI filament for less $15 \mathrm{~min}$ ), and (b) $0.6 \mathrm{~s}$ after electron impact ionization event and $4 \mathrm{~h}$ of ICR cell heating by the EI filament. Unimolecular decay product ions at $m / z 94(\square)$ and $m / z 92+121(\triangle)$ are also shown.

abundance). The $\left[\mathrm{A}_{\mathrm{r}}^{+}\right]_{0}$ value of 0.13 is in agreement (within experimental error) with the expected value of 0.11 for natural isotopic abundance; these results suggest that the isolated $\mathrm{M}_{\mathrm{ap}}^{+}$had little or no unreactive component toward $\mathrm{CT}$. The $\mathrm{CT}$ reaction rate constant for $\mathbf{M}_{\text {ap }}^{+}(m / z 136)$ with $\alpha$-pinene to give ${ }^{13} \mathrm{C}_{1} \mathbf{M}_{\text {ap }}^{+}$at $m / z$ 137 was $9.9 \times 10^{-10} \mathrm{~cm}^{3} \cdot$ molec $^{-1} \cdot \mathrm{s}^{-1}$ (using the total pressure for the carbon isotopomers of neutral $\alpha$-pinene in the ICR cell). The corrected partial pressure of the reactants (i.e., ${ }^{13} \mathrm{C}_{1}$ neutrals) yields a higher $\mathrm{CT}$ rate implying a long range and efficient charge-transfer [28].

The reaction of camphene molecular cation, $\mathrm{M}_{\mathrm{ca}}^{+}$, with camphene (Reactions 3, 4, Table 1 ) had a $\left[\mathrm{A}_{\mathrm{r}}^{+}\right]_{0}$ of $\sim 0.68$ (i.e., $\mathrm{R}_{\mathrm{U}} \sim 0.68$ ). Camphene, $\mathrm{M}_{\mathrm{ca}}^{+}$, SWIFT isolated $\sim 1.5 \mathrm{~s}$ after the EI event slowly dissociated to produce a fragment ion at $m / z 94$ which subsequently 
reacted with neutral camphene to yield protonated camphene, $\left[\mathrm{M}_{\mathrm{ca}}+\mathrm{H}\right]^{+}$, at $m / z=137$. The branching ratios for the formation of $m / z 94$ and all other product ions $(\mathrm{m} / \mathrm{z} 92$ and $\mathrm{m} / \mathrm{z} 121)$ from $\mathrm{m} / \mathrm{z} 136$ were $\sim 0.5$ and $\sim 0.18$, respectively. The rate constant for the reaction of $m / z 94$ with camphene was $\mathrm{k} \approx 1.7 \times$ $10^{-9} \mathrm{~cm}^{3} \cdot$ molec $^{-1} \cdot \mathrm{s}^{-1}$. After $\sim 200 \mathrm{~s}$ reaction time, no further unimolecular dissociation of $\mathrm{M}_{\mathrm{ca}}^{+}$was observed. In the $\mathrm{M}_{\mathrm{ca}}^{+}$reaction, the $\mathrm{M}_{\mathrm{ca}}^{+}$unimolecular time constant of $15 \mathrm{~s}$ for disappearance of 136 ions (Reaction 3, Table 1) was smaller than the pseudo first-order ion-molecule reaction time constant of $45 \mathrm{~s}$ for $94 \rightarrow 137$ (Reaction 4, Table 1); the $\mathrm{m} / \mathrm{z} 137$ only appeared at longer reaction times in accord with a two-step consecutive reaction of type shown in Scheme 2.

\section{m-Xylene CT and Variable Energy EI Experiments}

An event sequence similar to that shown in Figure 1d was used to study the CT reaction:

$106^{++}\left(\mathrm{M}_{m \text {-xyl }}^{++}\right)+$camphene $\rightarrow 136^{++}\left(\mathrm{M}_{\mathrm{ca}}^{+}\right)+m$-xylene.

CT from SWIFT isolated thermalized $m$-xylene radical cations at $m / z 106\left(\mathbf{M}_{m-x y l}^{++}\right)$to camphene occurred at a rate of $\sim 1.2 \times 10^{-9} \mathrm{~cm}^{3} \cdot \mathrm{molec}^{-1} \cdot \mathrm{s}^{-1}$ (Reactions 6, 7, Table 1). To thermalize the isolated $m$-xylene molecular cations $\left(\mathrm{M}_{m \text {-xyl }}^{++}\right)$, both unimolecular cooling and collisional cooling by neutrals (using additional pulse valve events not shown in Figure 1d) were used.

The reported literature value for camphene IE is " $<8.86 \mathrm{eV}^{\prime \prime}$ but the IE of $\sim 8.55 \mathrm{eV}$ for m-xylene [29] establishes an upper limit for the camphene IE to be $<8.55 \mathrm{eV}$. Presence of the camphene fragment ions at $m / z 94$ (loss of $\mathrm{C}_{3} \mathrm{H}_{6}$ from camphene molecular cation at $m / z$ 136) in $m$-xylene CT mass spectra (not shown here) suggests that the product camphene molecular cations contained internal energy above their IE. Hence, the IE of camphene should be below $8.55 \mathrm{eV}$. These results are in qualitative agreement with the ionization threshold observed in the photoelectron spectrum (PES) of camphene $(\sim 8.0 \mathrm{eV}$ for ionization at the $\pi$ bond) [6].

A nominal $8 \mathrm{eV}$ EI mass spectrum of camphene contained only two major ions, $m / z 94$ and 136; whereas a nominal $10 \mathrm{eV}$ camphene mass spectrum had $\mathrm{m} / \mathrm{z} 93$ as the base peak and both $\mathrm{m} / \mathrm{z} 94 \quad(\sim 10 \%$ relative abundance) and 136 became relatively minor peaks. Performing low-resolution $(\Delta \mathrm{E} \sim 0.05 \mathrm{eV})$ variable energy EI on camphene showed that the appearance energy for $m / z 94$ was higher than the ionization energy by $\sim 0.5 \mathrm{eV}$. The PES band gap between $\pi$ (lowest IE) and $\sigma$ (higher IE) ionization of camphene is $\sim 1.5 \mathrm{eV}$ [6]. The literature PES data combined with our low-energy EI camphene MS data suggests that the camphene $\mathrm{m} / \mathrm{z}$ 136 ions undergoing BIRD originate from the electronic ground state of camphene ionized at the $\pi$ bond; the $\mathrm{m} / \mathrm{z}$ 94 dissociation channel lies $\sim 0.5 \mathrm{eV}$ above the ground vibrational state.
Fragment Ions of $\alpha$-Pinene and Camphene $(\mathrm{m} / \mathrm{z} 93$ and 121)_General Comments

We used SWIFT isolation (0.5 s after the $24 \mathrm{eV}$ electron impact event) to monitor fragment ion reactivities. The main observed (SCI) products were protonated terpenes $[\mathrm{M}+\mathrm{H}]^{+}$; a minor product channel (viz. $m / z$ 81, Reaction 10, Table 1) was present in addition to the $\mathrm{m} / \mathrm{z}$ 137 product ion channel. At longer reaction delays $(>200 \mathrm{~s})$ and reactant neutral pressure of $\sim 5 \times 10^{-9}$ torr, condensation and association product ions were observed (e.g., Reactions 10, 11, 13, 15, 16, Table 1).

Reactions of fragment ions at $\mathrm{m} / \mathrm{z} 93$. Figure 3 shows temporal plots of SWIFT isolated fragment ions of $\alpha$-pinene and camphene at $m / z 93(\mathbf{O})$ reacting with their $\alpha$-pinene (Figure 3a) and camphene (Figure 3b) neutral counterparts, respectively. The fragment ions at $m / z 93$ for both $\alpha$-pinene and camphene yielded SCI protonated parent ions $(\bigcirc)$. The PT rate constant for $\alpha$-pinene fragment ion at $m / z 93$ with $\alpha$-pinene (i.e., [93] ${ }^{+}+\mathrm{M} \rightarrow$ $\left.[\mathrm{M}+\mathrm{H}]^{+}+92\right)$ was $4.2 \times 10^{-10} \mathrm{~cm}^{3} \cdot \mathrm{molec}^{-1} \cdot \mathrm{s}^{-1}$; the PT branching ratio of $m / z 93\left(\mathrm{R}_{\mathrm{PT} 93}\right)$ was $\sim 0.70$ (Figure $3 \mathrm{a}$ and Reaction 8 in Table 1). Other reaction channels were $m / z 81\left(\diamond, R_{C} \sim 0.25\right.$, Reaction 10, Table 1) and a minor charge exchange product to yield $m / z 136, \mathbf{M}^{+}$ $\left(\boldsymbol{\Delta}, \mathrm{R}_{\mathrm{CT}} \sim 0.05\right.$, Reaction 9, Table 1).

The $\alpha$-pinene product fragment ion at $m / z 81$ further reacted with the neutral $\alpha$-pinene to yield a number of minor condensation product ions at $m / z$ 95, 121, and 161 at a rate of $5.2 \times 10^{-11} \mathrm{~cm}^{3} \cdot \mathrm{molec}^{-1} \cdot \mathrm{s}^{-1}$ (Reaction 11, Table 1). The abundances of these minor product ions were summed together and are shown in Figure $3 \mathrm{a}$ as "other products" $(\nabla)$. The PT rate constant for camphene fragment ions at $m / z 93$ with the neutral camphene was $5.9 \times 10^{-10} \mathrm{~cm}^{3} \cdot \mathrm{molec}^{-1} \cdot \mathrm{s}^{-1}$ and branching ratios for the production of protonated camphene and other products were $R_{\mathrm{PT}} \sim 0.88$ and $\mathrm{R}_{\mathrm{C}} \sim 0.12$ (Reactions 12, 13, Table 1), respectively. A minor product channel for camphene 93 fragment ion was the formation of $\mathrm{m} / \mathrm{z} 81\left(\mathrm{k}=1.3 \times 10^{-9} \mathrm{~cm}^{3} \cdot \mathrm{molec}^{-1} \cdot \mathrm{s}^{-1}\right)$. Unlike the $\alpha$-pinene system, the $m / z 81$ produced by the reaction of $m / z 93$ camphene fragment ion with camphene was a terminal product ion (see Figure $3 b$ ). The terpene $m / z 81$ should not PT at a measurable rate in the presence of either camphene $\left(\mathrm{PA} \sim 210 \mathrm{kcal} \cdot \mathrm{mol}^{-1}\right.$, this work) or $\alpha$-pinene (PA $\sim 210 \mathrm{kcal} \cdot \mathrm{mol}^{-1}$, this work) if the conjugate base of $\mathrm{m} / \mathrm{z} 81$ is 1-methyl-3methylenecyclobutene $\left(\mathrm{PA}=213.0 \mathrm{kcal} \cdot \mathrm{mol}^{-1}\right.$ [29] .

Possible candidates for the conjugate base of terpene $\mathrm{m} / \mathrm{z} 93$ fragment ions (corresponding to the loss of $\left(\mathrm{CH}_{3}\right)_{2} \mathrm{C}$ and $\mathrm{H}$ from $\mathrm{M}^{+}$followed by hydride shifts and ring opening/closure) is 2,5-norbornadiene (PA = $203.0 \mathrm{kcal} \cdot \mathrm{mol}^{-1}$ [29] and 3-methylene 1,4-hexadiene (PA not known). The camphene fragment ion at $m / z 93$ could be the result of a double fragmentation mechanism: loss of a $\mathrm{CH}_{3}$ group to make an allyl cation followed by loss of $\mathrm{C}_{2} \mathrm{H}_{4}$ (the ethano bridge) to give initially 2-( $\left.\mathrm{CH}_{2}^{+}\right)-3-\left(\mathrm{CH}_{3}\right)$-cyclopentadiene and possibly 


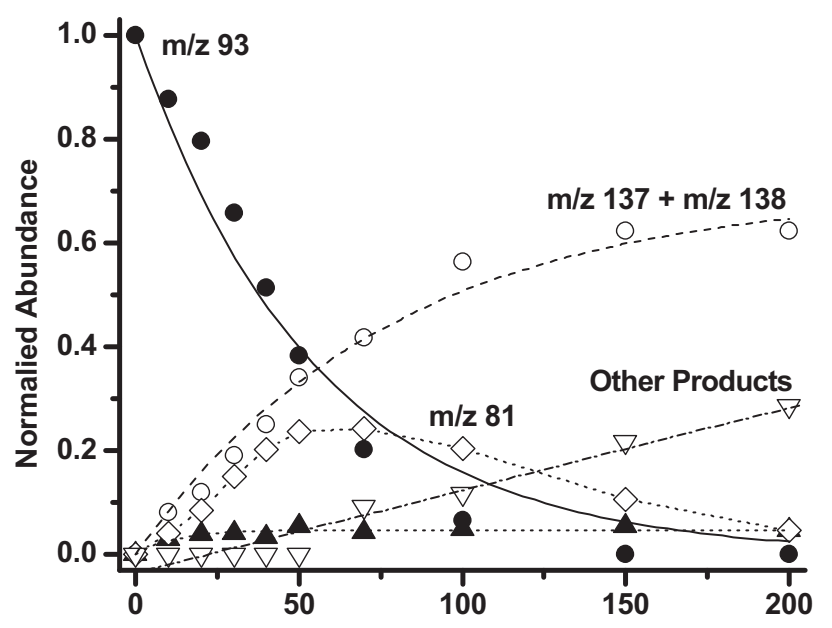

(a)

Reaction Delay Time (s)

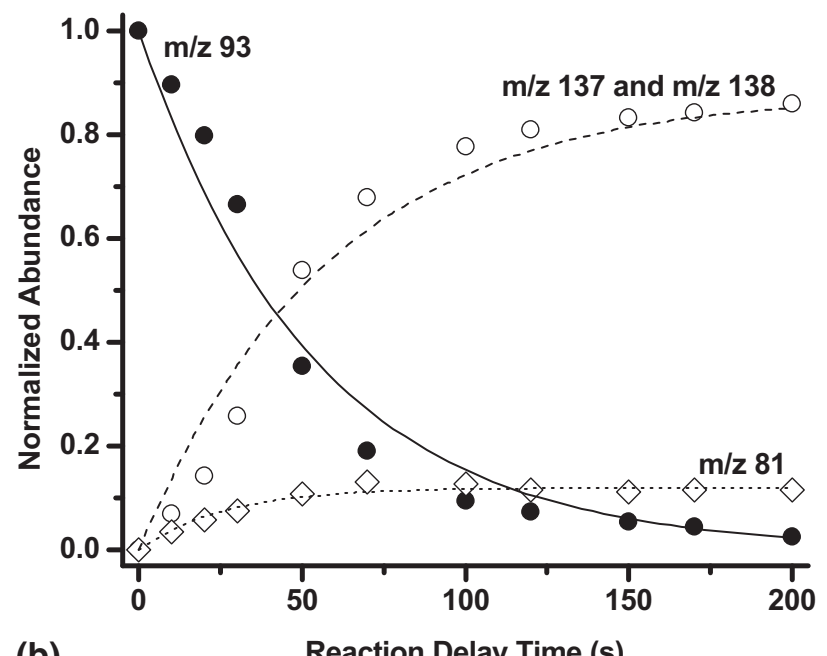

(b)

Reaction Delay Time (s)

Figure 3. Temporal plots showing reactions of (a) $\alpha$-pinene and (b) camphene fragment ions at $\mathrm{m} / \mathrm{z} 93$ with their respective parent neutrals at $P=4.7 \times 10^{-9}$ and $4.9 \times 10^{-9}$ torr, respectively. The reaction of $\alpha$-pinene $\mathrm{m} / \mathrm{z} 93(\bullet)$ with $\alpha$-pinene yielded product ions at $m / z 81(\diamond), m / z 136$ (molecular cation, $\mathbf{\Delta}$ ), $m / z 137$ and 138 (protonated $\alpha$-pinene, $\bigcirc$ ) and others (a number of low abundance product ions at $m / z 93,95,121$, and 161 summed together as $\nabla$ ). The reaction of camphene $\mathrm{m} / \mathrm{z} 93(\mathbf{\bullet})$ with camphene yielded product ions at $m / z 137 / 138$ (protonated camphene, $\bigcirc$ ), and $\mathrm{m} / \mathrm{z}$ $81(\diamond)$.

subsequent tautomerizations. Basic and Harrison [14] have determined the identity of the EI fragment ion at $\mathrm{m} / \mathrm{z} 93$ from selected terpenes as protonated 1,3,5cycloheptatriene. The PA of 1,3,5-cycloheptatriene (protonated at C-1) has been determined to be $199 \pm 1 \mathrm{kcal}$ $\cdot \mathrm{mol}^{-1}$ by FT-ICR MS [30]. Considering the available PA $[29,30]$ and kinetics data (this work, the estimated PA for either $\alpha$-pinene or camphene is $\sim 210 \mathrm{kcal}$. $\mathrm{mol}^{-1}$ ), terpene fragment ions at $\mathrm{m} / \mathrm{z} 93$ could be either protonated 2,5-norbornadiene, protonated 1,3,5-cycloheptatriene, or a mixture of the two. It should be noted that terpene fragment ion population at $\mathrm{m} / \mathrm{z} 93$ could contain other species with PA values lower than $\sim 210$ $\mathrm{kcal} \cdot \mathrm{mol}^{-1}$. In separate experiments, protonated tolu- ene at $\mathrm{m} / \mathrm{z} 93\left(\mathrm{PA}_{\text {(toluene) }}=187.4 \mathrm{kcal} \cdot \mathrm{mol}^{-1}\right)[29]$ protonated both camphene and $\alpha$-pinene at near unit reaction efficiency (cf. $\sim \leq 0.3$ reaction efficiency for Reactions 8 and 12, Table 1); these results suggest that very little or no protonated toluene was present in the terpene $m / z 93$ fragment ion populations.

Reactions of fragment ions at $\mathrm{m} / \mathrm{z} 121$. Figure 4 contains temporal plots of SWIFT isolated fragment ions of $\alpha$-pinene and camphene at $m / z 121(\bullet)$ reacting with their neutral parent $\alpha$-pinene (Figure $4 \mathrm{a}$ ) and camphene (Figure 4b) counterparts, respectively. Approximately $42 \%$ of the $\alpha$-pinene fragment ions at $m / z 121$ (Figure $4 a$ ) reacted with neutral $\alpha$-pinene to yield $m / z 137(\bigcirc)$ as the sole product channel at a rate of $5.5 \times 10^{-10} \mathrm{~cm}^{3}$. molec $^{-1} \cdot \mathrm{s}^{-1}$ (reaction efficiency $\sim 0.25$, Reaction 14 , Table 1). Conversely, $\sim 15 \%$ (cf. $\sim 42 \%$ for $\alpha$-pinene) of
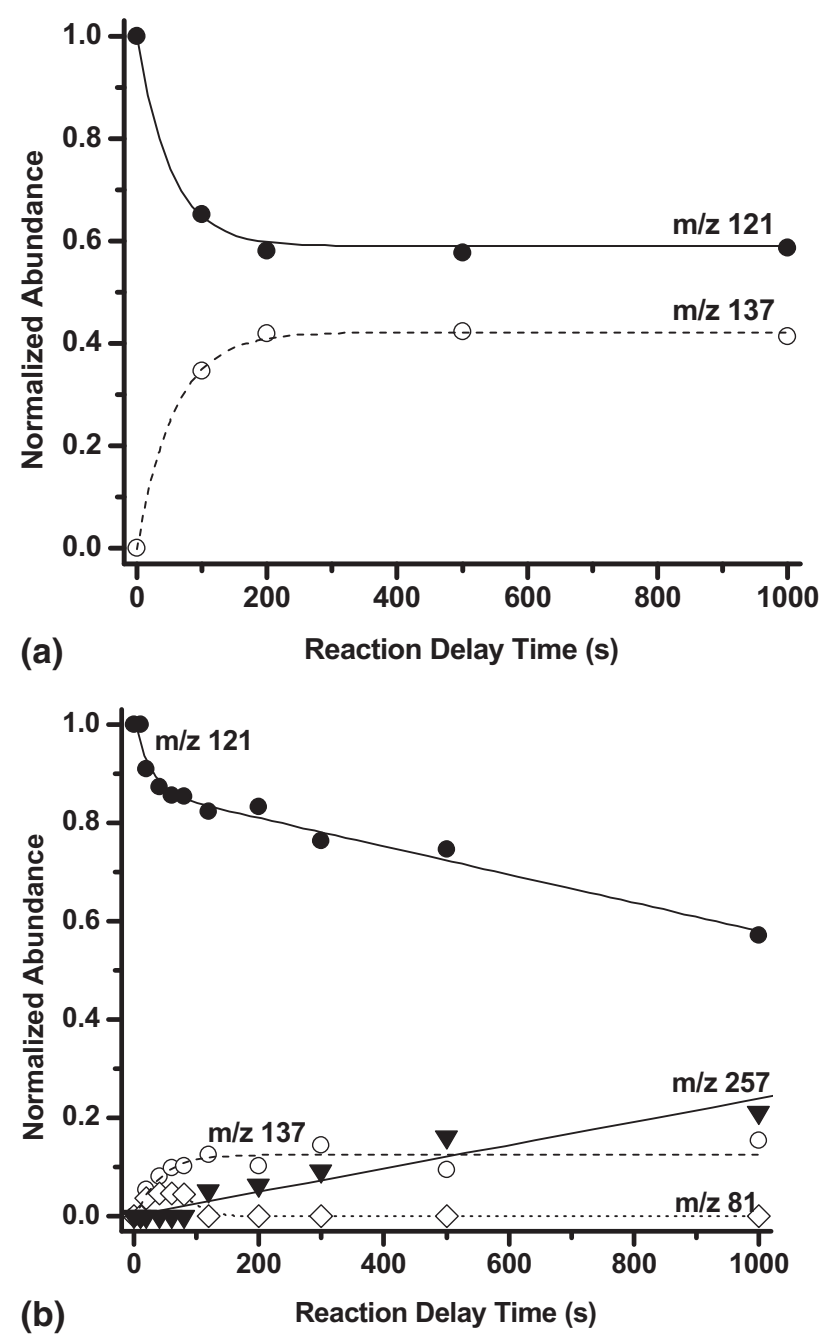

Figure 4. Temporal plots showing reactions of (a) $\alpha$-pinene and (b) camphene fragment ions at $m / z 121$ with their respective parent neutrals at $P=4.7 \times 10^{-9}$ torr. The reaction of $\alpha$-pinene $\mathrm{m} / z 121$ (๑) with $\alpha$-pinene yielded only product ions at $\mathrm{m} / \mathrm{z} 137$ and 138 (protonated $\alpha$-pinene, $\bigcirc$ ). The reaction of camphene $\mathrm{m} / \mathrm{z} 121(\bullet)$ with camphene yielded product ions at $\mathrm{m} / \mathrm{z}$ 137/138 (protonated camphene, $\bigcirc), m / z 81(\diamond)$, and $m / z 257(\boldsymbol{\nabla})$. 
the camphene $m / z 121$ ions reacted with neutral camphene to yield two first-order product channels, viz. $\mathrm{m} / \mathrm{z}$ $81\left[\mathrm{M}+\mathrm{H}-\mathrm{C}_{4} \mathrm{H}_{8}\right]^{+}(\diamond)$ and $137[\mathrm{M}+\mathrm{H}]^{+}(\bigcirc)$, at a rate of $1.1 \times 10^{-9} \mathrm{~cm}^{3} \cdot \mathrm{molec}^{-1} \cdot \mathrm{s}^{-1}$ (reaction efficiency $\sim 0.50$, Figure $4 \mathrm{~b}$ and Reaction 15 in Table 1 ). After $200 \mathrm{~s}$ of reaction, the camphene $m / z 121$ fragment ions disappeared more slowly at an apparent rate $\left(\mathrm{k}_{\mathrm{app}}\right)$ of $\sim 8.8 \times$ $10^{-12} \mathrm{~cm}^{3} \cdot \mathrm{molec}^{-1} \cdot \mathrm{s}^{-1}$ to give an association product ion at $\mathrm{m} / \mathrm{z} 257(\boldsymbol{\nabla})$ (Reaction 16, Table 1). In addition, $\mathrm{m} / \mathrm{z} 81$ reacted with camphene to give an association product at $\mathrm{m} / \mathrm{z} 217\left[2 \mathrm{M}+\mathrm{H}-\mathrm{C}_{4} \mathrm{H}_{8}\right]^{+}$(not shown in Table 1 or Figure $4 b$ ).

From our observations, the $m / z 121$ from $\alpha$-pinene or camphene produced by $24 \mathrm{eV}$ EI has at least three reaction channels: a PT channel to give $m / z 137$, a channel to give $m / z 81$, and an unreactive channel. Some possible structures for $m / z 121$ ion species are discussed below.

All of the protonated authentic mesitylene sample $\left(\mathrm{m} / \mathrm{z} 121,100 \%\right.$ reactive, $\left.\mathrm{PA}_{(\text {mesitylene })}=199.9 \mathrm{kcal} \cdot \mathrm{mol}^{-1}\right)$ proton transferred to $\alpha$-pinene and camphene at unit reaction efficiency (data not shown in Table 1); this reaction efficiency can be compared with the estimated PT reaction efficiencies of 0.5 (or less) for Reactions 14, 15 in Table 1. Therefore, neither $\alpha$ pinene nor camphene fragment ions at $m / z 121$ contain protonated mesitylene as a major PT reactive component. Examination of the online NIST Chemistry Webbook [29] yielded no PA data for $\mathrm{C}_{9} \mathrm{H}_{12}$ compounds (other than mesitylene, $n$-propylbenzene, and $i$-propylbenzene) having PAs $<210 \mathrm{kcal} \cdot \mathrm{mol}^{-1}$. Hence, based on the limited PA data, possible structures for the PT reactive components of terpene $\mathrm{m} / \mathrm{z}$ 121 fragment ions can not be determined solely on PA considerations.

The ion at $m / z 121$ could be formed from camphene $\mathrm{M}^{+}$by the loss of a methyl group by simple bond cleavage to give protonated bicyclo[2.2.1] heptane, 2,3-bis(methylene) and from $\alpha$-pinene $\mathrm{M}^{+}$by the loss of a methyl group followed by ring opening and $\mathrm{H}$ shift to yield 1,2,4-trimethylphenonium. The IE for 3,3-dimethyl6-methylene-1,4-cyclohexadiene (an isomer of deprotonated 1,2,4-trimethylphenonium, $\mathrm{m} / \mathrm{z} 121$ ) is $8.0 \mathrm{eV}$ [29]. From the discussion below on the PA versus IE linear correlation, the PA for 3,3-dimethyl-6-methylene-1,4cyclohexadiene is estimated to be higher than either $\alpha$-pinene or camphene $\geq 212 \mathrm{kcal} \cdot \mathrm{mol}^{-1}$. Ion structures for $m / z 121$ such as, 1,2,4-trimethylphenonium of possibly higher conjugate base proton affinity (e.g., $\geq 215$ $\mathrm{kcal} \cdot \mathrm{mol}^{-1}$ ) may be responsible for the PT nonreactivity or the slow kinetics observed at long reaction times for terpene fragment ions at $m / z 121$.

The $\mathrm{M}^{+}$of either $\alpha$-pinene or camphene could lose a methyl group by simple bond cleavage, followed by ring breaking, hydride, and methylene group shifts to give protonated 3-methylene-1,5-dimethylcyclohexene. The PA for 3-methylene-1,5,5-trimethylcyclohexene (a terpene isomer) is $216.3 \mathrm{kcal} \cdot \mathrm{mol}^{-1}$ [29]. Replacing one of the methyl groups at the 5 position by $\mathrm{H}$ (to give 3-methylene-1,5-dimethylcyclohexene) may reduce the PA marginally by $<1.5 \mathrm{kcal} \cdot \mathrm{mol}^{-1}$ to $>\sim 215 \mathrm{kcal} \cdot \mathrm{mol}^{-1}$ which is $\sim 3$ to $5 \mathrm{kcal} \cdot \mathrm{mol}^{-1}$ higher than the estimated PA of either camphene or $\alpha$-pinene. The presence of large unreactive fractions (toward PT channel only) of $\alpha$-pinene $(\sim 0.58$, initial $200 \mathrm{~s}$ in Figure $4 \mathrm{a})$ and camphene $(\sim 0.85$, initial $200 \mathrm{~s}$ in Figure $4 b$ ) fragment ions at $m / z \quad 121$ and in the presence of their parent terpene can be accounted for if the unreactive component of $\mathrm{m} / \mathrm{z} 121$ is protonated 3-methylene-1,5-dimethylcyclohexene; the PT channel to give protonated parent terpene is endothermic by $\sim 3$ to $5 \mathrm{kcal} \cdot \mathrm{mol}^{-1}$ and therefore may proceed at immeasurable reaction rates (Figure 4).

\section{Proton Affinities of $\alpha$-Pinene and Camphene}

We used a PA group additivity scheme [31], PA versus IE linear correlation [32], literature DFT calculations [33], PA bracketing and PT kinetics to estimate the PA for $\alpha$-pinene or camphene be $\sim 210 \pm 2 \mathrm{kcal} \cdot \mathrm{mol}^{-1}$. There is insufficient data available in the literature [29] to use a PA group additivity scheme on $\alpha$-pinene or a PA versus IE linear correlation analysis on camphene; for example, IE of camphene is not well established [29] and PA values for $\alpha$-pinene like ring structures are not readily available.

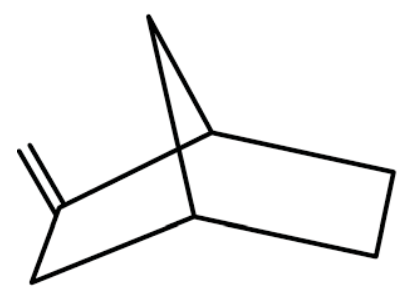

2-Methylenenorbornane

3

A molecule with an identical ring structure to camphene (2) is 2-methylenenorbornane (3) $\left(\mathrm{C}_{8} \mathrm{H}_{12}\right)$ but lacking the 2 methyl substituents on the $\alpha$ carbon to the $>\mathrm{C}=\mathrm{CH}_{2}$ group. Unlike ketones, there is a lack of PA data on alkenes in the literature [29] to calculate group additivity PA increments for alkenes. Instead, we used a ketone as a reasonable isoelectronic approximation for an alkene. The pairs of ketones used to calculate methyl group PA increments included: 2,2,4,4-tetramethyl-3pentanone and 3-pentanone $\left(\Delta \mathrm{PA}=5.9 \mathrm{kcal} \cdot \mathrm{mol}^{-1}\right.$ with a difference of 4 methyl groups); 2,2,4-trimethyl3-pentanone and 3-pentanone $\left(\Delta \mathrm{PA}=4.8 \mathrm{kcal} \cdot \mathrm{mol}^{-1}\right.$ with a difference of 3 methyl groups); 2,4-dimethyl-3pentanone and 3-pentanone $\left(\Delta \mathrm{PA}=3.2 \mathrm{kcal} \cdot \mathrm{mol}^{-1}\right.$ with a difference of 2 methyl groups); 3,3-dimethyl-2butanone and 2-butanone $\left(\Delta \mathrm{PA}=3.1 \mathrm{kcal} \cdot \mathrm{mol}^{-1}\right.$ with a difference of 2 methyl groups). Considering the four ketone pairs, an average of $\sim 1.6 \mathrm{kcal} \cdot \mathrm{mol}^{-1}$ for each 


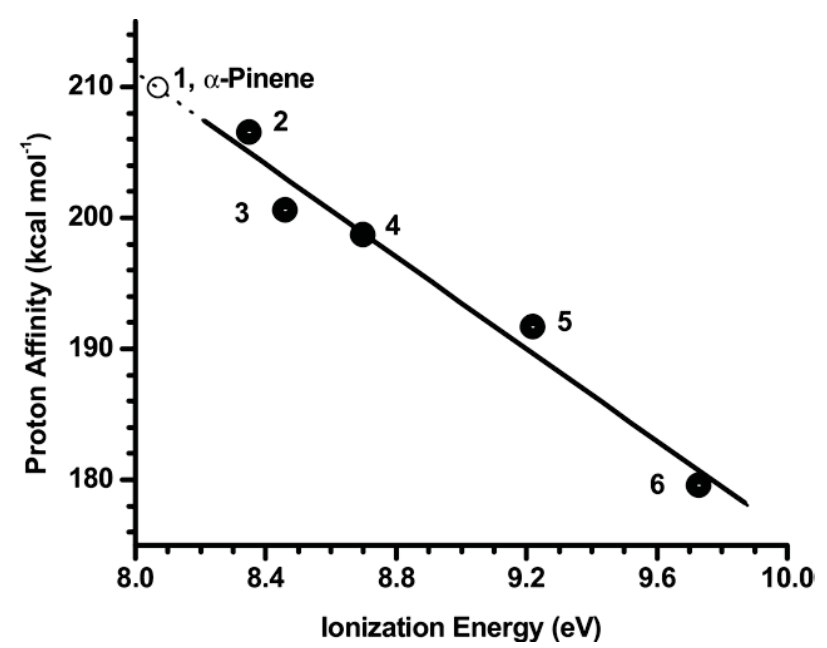

Figure 5. Estimating the proton affinity (PA) of $\alpha$-pinene $(O)$ from the linear regression plot of adiabatic IE versus PA for alkenes $(-)$ : adiabatic ionization energies for all entries and proton affinities for labels 2 ( $\alpha$-methylstyrene), 3 (styrene), 4 (methylenecyclopentane), 5 (i-butene), and 6 (propene) are from the online Chemistry Webbook [29].

additional methyl group is estimated. The $>\mathrm{C}=\mathrm{CH}_{2}$ group (e.g., in camphene) is isoelectronic to a ketone group $(>\mathrm{C}=\mathrm{O})$ and therefore methyl substitution for $\mathrm{H}$ on the $\alpha$-carbon for either $>\mathrm{C}=\mathrm{CH}_{2}$ or $>\mathrm{C}=\mathrm{O}$ should show similar group PA increments.

Using methyl group additivity increments $(\sim 3.2 \mathrm{kcal}$ - $\mathrm{mol}^{-1}$ for two methyl groups) to ketone PA (for the $\alpha$-carbon methyl group substitution) as a model and the known PA of 2-methylenenorbornane [29], the PA of camphene is estimated to be $\left(205.7 \mathrm{kcal} \cdot \mathrm{mol}^{-1}+3.2\right.$ $\mathrm{kcal} \cdot \mathrm{mol}^{-1}$ ) $\sim 209 \mathrm{kcal} \cdot \mathrm{mol}^{-1}$ [31].

PA versus IE linear correlation. Aubry and Holmes presented a brief review of the correlation schemes for different homologous series to relate various gas-phase thermochemical data [32]. For example, there is a linear relationship [34, 35] between PAs and IEs for series of oxygen compounds. In principal, this type of a linear relationship can be extended to alkenes. A plot of proton affinity versus adiabatic ionization energies for model alkenes with a linear correlation coefficient of 0.97 is shown in Figure 5. Using the known IE for $\alpha$-pinene of $8.07 \mathrm{eV} \mathrm{[29]} \mathrm{and} \mathrm{performing} \mathrm{linear} \mathrm{regres-}$ sion analysis on the data in Figure 5, the PA for $\alpha$-pinene is estimated as $\sim 210 \mathrm{kcal} \cdot \mathrm{mol}^{-1}$.

DFT calculations of PA. A DFT calculation [33] places the PA of camphene $\left(213.4 \mathrm{kcal} \cdot \mathrm{mol}^{-1}\right) \sim 1 \mathrm{kcal} \cdot \mathrm{mol}^{-1}$ below that of $\alpha$-pinene $\left(\mathrm{PA}=214.2 \mathrm{kcal} \cdot \mathrm{mol}^{-1}\right)$. It should be noted that DFT calculated absolute PAs for alkenes may be systematically higher and this particular deficiency in DFT has been noted by Smith and Radom [36]. On the other hand, relative DFT calculated PAs are generally reliable for homologues. In summary, both DFT calculations and PA estimations show that the
PA of $\alpha$-pinene and camphene are comparable to within $2 \mathrm{kcal} \cdot \mathrm{mol}^{-1}$.

PA bracketing experiments. PT between base pairs of pyrrole with either $\alpha$-pinene or camphene was not observed in either direction (i.e., $\left\{[\text { Pyrrole }+\mathrm{H}]^{+}+\right.$ Terpene $\}$ and $\left\{[\text { Terpene }+\mathrm{H}]^{+}+\right.$Pyrrole $\}$reactions at neutral pressures of $\sim 1 \times 10^{-8}$ torr and reaction delay times of up to $500 \mathrm{~s}$ were immeasurably slow). This observation suggests that the PAs of $\alpha$-pinene, camphene or pyrrole $\left(209.2 \mathrm{kcal} \cdot \mathrm{mol}^{-1}\right.$ from reference [29] are similar and there is a positive activation barrier $\left(\sim 2.7 \mathrm{kcal} \cdot \mathrm{mol}^{-1}\right.$ for less than $1 \%$ reaction efficiency at room temperature) [37] for PT.

Estimate of the lower PA value for ck-pinene. Protonated $\alpha$-pinene did not proton transfer to 5-nonanone (PA = $204.0 \mathrm{kcal} \cdot \mathrm{mol}^{-1}[29]$ at an observable rate $(\leq 1 \%$ extent of reaction at the noise level) at a neutral 5-nonanone pressure of $5.0 \times 10^{-9}$ torr (ion gauge reading) and up to $500 \mathrm{~s}$ reaction delay (Reaction 17, Table 1). The corresponding estimated proton transfer reaction efficiency $(\eta)$ was $\leq 2.2 \times 10^{-4}$. The estimated reaction efficiency of $\eta \leq 2.2 \times 10^{-4}$ implies an endoergocity $(\Delta \mathrm{G} \approx-\mathrm{RT} \ln \{\eta\})$ of $\geq 5 \mathrm{kcal} \cdot \mathrm{mol}^{-1}$ for the PT reaction from protonated $\alpha$-pinene to 5-nonanone [37]. Therefore, excluding minor entropy contributions to $\Delta \mathrm{G}$, the PA of $\alpha$-pinene is estimated to be $\geq 209 \mathrm{kcal} \cdot \mathrm{mol}^{-1}$.

Estimate of the upper PA value for camphene. Figure 6 shows the reaction of SWIFT isolated protonated camphene (at $\mathrm{m} / \mathrm{z}$ $137,0)$ with N-N-dimethylformamide to yield initially pro-

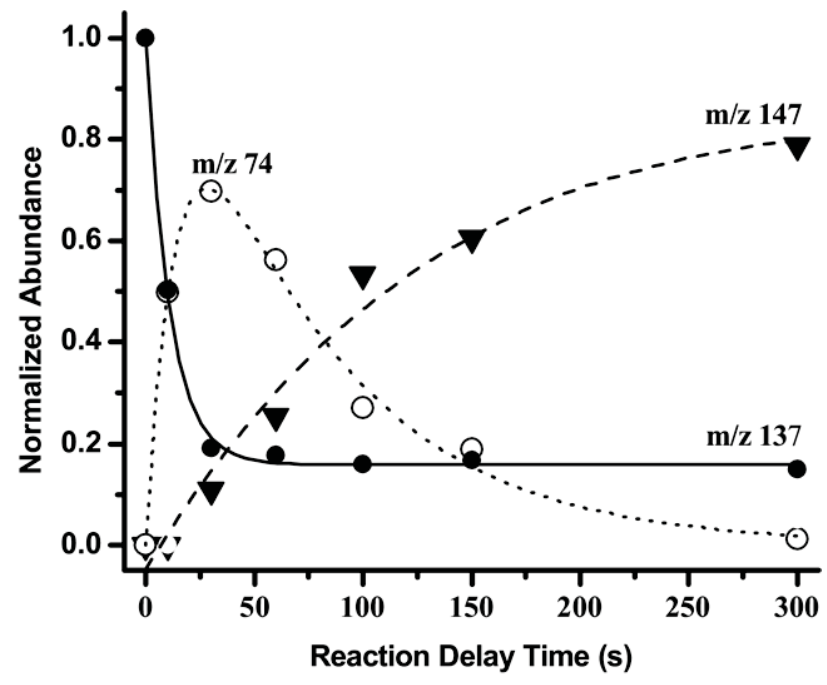

Figure 6. Temporal plots for proton transfer reaction of protonated camphene $(m / z$ 137, $)$ with $\mathrm{N}, \mathrm{N}$-dimethylformamide $(\mathrm{NNDMF})$ at a neutral pressure of $4.4 \times 10^{-9}$ torr. Observed ion-molecule reaction products included protonated NNDMF at $m / z 74(\bigcirc)$ and an association product ion at $\mathrm{m} / \mathrm{z} 147(\boldsymbol{\nabla}$, the protonated dimer of NNDMF). Note that a significant fraction of protonated camphene was unreactive toward proton transfer to NNDMF (i.e., the conjugate base of this component must have a higher proton affinity than the neutral NNDMF). 
tonated N-N-dimethylformamide (at $m / z 74, \bigcirc$ ) and subsequently an association product ion at $m / z 147$ (the proton bound dimer of N-N-dimethylformamide, $\mathbf{\nabla}$ ). Thermalized protonated camphene was isolated $50 \mathrm{~s}$ after the EI/SCI event. Protonated camphene efficiently proton transferred $(\mathrm{k}$ $=1.1 \times 10^{-9} \mathrm{~cm}^{3} \cdot$ molec $^{-1} \cdot \mathrm{s}^{-1}, \sim 50 \%$ reaction efficiency, Reaction 19, Table 1) to N-N-dimethylformamide (PA = $212.1 \mathrm{kcal} \cdot \mathrm{mol}^{-1}$ ). Excluding entropy considerations and in the absence of activation barriers, this observation suggests that the PA of camphene is $\leq 212 \mathrm{kcal} \cdot \mathrm{mol}^{-1}$. A 50\% PT reaction efficiency [37] would imply that the gas-phase basicity of the conjugate base of protonated camphene species and N-N-dimethylformamide are identical.

In the PT reaction of protonated camphene with N-N-dimethylformamide, about $15 \%$ of the SWIFT isolated protonated camphene was unreactive. The unreactive protonated camphene component noted here and elsewhere could have resulted if the SCI protonation exothermicity were sufficient to isomerize protonated camphene. For example, protonation of camphene at the secondary alkene carbon (e.g., by a low mass fragment ion such as $\mathrm{C}_{3} \mathrm{H}_{7}^{+}$of high Brönsted acidity, $\mathrm{PA}_{\text {propene }}=179.6 \mathrm{kcal} \cdot \mathrm{mol}^{-1}$ ) followed by isomerization could yield a new conjugate base with a higher PA than that of N-N-dimethylformamide. Similar isomerization phenomenon has been observed in the protonation of 1,3,5-cycloheptatriene by strong Brönsted acids [30].

\section{PT Reactions Between $\alpha$-Pinene and Camphene}

It is impossible to observe directly the PT from one protonated terpene (at $\mathrm{m} / \mathrm{z} 137$ ) to another isomeric terpene by FT-ICR MS (reactant and product ions have the same mass). One way to overcome this limitation is to use isotope "tagging" of the reactant ion [38].

In a series of experiments, either $\alpha$-pinene or camphene was ionized by a $\sim 10 \mathrm{~ms} 24 \mathrm{eV}$ electron pulse event after the initial $3 \mathrm{~ms}$ pulsed valve sample introduction. Additional sample pulsed valve introductions were used to promote extensive SCI and ion-cooling. A longer delay time of $3.2 \mathrm{~s}$ for $\alpha$-pinene together with additional $\alpha$-pinene sample introduction pulsed valve events (cf. camphene) were required to produce abundant protonated $\alpha$-pinene (see also Figure 7 and related discussion).

In separate experiments, the SWIFT isolated ions at $\mathrm{m} / \mathrm{z} 138$ (i.e., ${ }^{13} \mathrm{C}_{1}$ tagged protonated terpene molecules) were allowed to PT with either camphene or $\alpha$-pinene neutrals to give protonated terpenes (Reactions 23 and 25, Table 1). Major camphene ionmolecule reaction products included ions at $\mathrm{m} / \mathrm{z} 81$ and 137 . Higher order consecutive reaction products were also observed in the ${ }^{13} \mathrm{C}_{1}$ tagged protonated $\alpha$-pinene/camphene reaction couple (Reactions 23, 24, Table 1).

Protonated ${ }^{13} \mathrm{C}_{1} \quad \alpha$-pinene population reacted with neutral camphene to yield protonated camphene at $\mathrm{m} / \mathrm{z}$

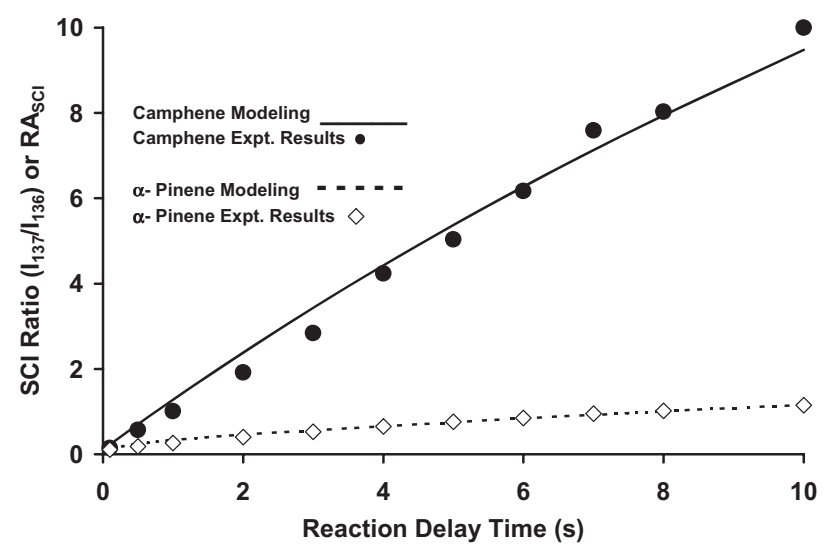

Figure 7. Temporal evolution of $1_{137} / l_{136}$ ratio (Terpene SCI Pressure $3.5 \times 10^{-8}$ torr). Experimentally observed $(\diamond, \bullet)$, and model predicted (---, -) temporal evolutions of $\mathrm{m} / \mathrm{z}$ 137: $\mathrm{m} / \mathrm{z} 136$ SCI ratio $\left(\mathrm{RA}_{\mathrm{SCI}}\right)$ for $\alpha$-pinene and camphene $\mathrm{SCI}$, respectively (at corresponding natural terpene pressure of $\sim 3.5 \times 10^{-8}$ torr).

$137\left(\mathrm{R}_{\mathrm{PT}} \sim 0.40\right)$, other product ions at $m / z 121,217$, and $273\left(\mathrm{R}_{\mathrm{IM}} \sim 0.27\right)$; the remaining $\sim 33 \%$ of protonated ${ }^{13} \mathrm{C}_{1} \alpha$-pinene were inert $\left(\mathrm{R}_{\mathrm{UR}} \sim 0.33\right)$. The rate constant for disappearance of protonated ${ }^{13} \mathrm{C}_{1} \alpha$-pinene was $1.6 \times 10^{-10} \mathrm{~cm}^{3} \cdot \mathrm{molec}^{-1} \cdot \mathrm{s}^{-1}$ (Reaction 23, Table 1). The camphene $\mathrm{m} / \mathrm{z} 137$ (initial product) subsequently reacted with the neutral camphene to produce an association product ion at $m / z 273\left[(\text { Camphene })_{2}+\mathrm{H}\right]^{+}$at an apparent bimolecular rate constant of $1.6 \times 10^{-11}$ $\mathrm{cm}^{3} \cdot$ molec $^{-1} \cdot \mathrm{s}^{-1}$ (Reaction 24, Table 1). A minor condensation product ion at $m / z 217$ [(Camphene $)_{2}+\mathrm{H}$ $\left.-\mathrm{C}_{4} \mathrm{H}_{8}\right]^{+}$was also formed. The 0.67 entry for the reactive fraction (Reaction 24, Table 1) represents the sum of all reaction channel branching ratios of the initially isolated protonated ${ }^{13} \mathrm{C}_{1} \alpha$-pinene $(\mathrm{m} / \mathrm{z} 138)$ population. The intermediate protonated camphene product ions $(\mathrm{m} / \mathrm{z} 137)$ were all reactive towards forming association $(\mathrm{m} / \mathrm{z} 273)$ and condensation $(m / z 217)$ products.

In contrast, $\sim 35 \%$ of the protonated ${ }^{13} \mathrm{C}_{1}$ camphene (SWIFT isolated $\sim 1.4 \mathrm{~s}$ after the EI event) reacted with $\alpha$-pinene by PT to give protonated $\alpha$-pinene $(m / z 137)$ as the sole product ion at a rate of $3.3 \times 10^{-10} \mathrm{~cm}^{3}$. molec $^{-1} \cdot \mathrm{s}^{-1}$ (Reaction 25 in Table $1, \mathrm{R}_{\mathrm{PT}} \sim 0.35$ ). Based on these PT reactions, it is difficult to ascertain whether camphene or $\alpha$-pinene has the higher PA. Interpretation of the experimental results is complicated due to (1) the presence of unreactive ${ }^{13} \mathrm{C}_{1}$ protonated terpene isomers, (2) SCI by different fragment ions in the EI mass spectrum of varying Brönsted acidities, (3) presence of multiple protonation sites, (4) potential isomerization of the protonated terpenes by neutral collisions, and (5) potentially slow PT reaction kinetics between carbon bases. Hence, the PT rate constants may not be useful to calculate accurate $\Delta \mathrm{G}$ for the proton exchange between camphene and $\alpha$-pinene; however, ${ }^{13} \mathrm{C}_{1}$ tagging experiments suggest that the gas-phase basicities of $\alpha$-pinene and camphene are comparable. 


\section{Other Consecutive and Minor Reaction Channels}

In addition to $\mathrm{CT}$ and PT reactions, a number of condensation (e.g., Reaction 10, Table 1) and association reactions (e.g., Reactions 11, 16, 20 and 24, Table 1) were observed at longer reaction delay times. For example, protonated N-N-dimethylformamide $(\mathrm{m} / \mathrm{z}$ 74) reacted with $\mathrm{N}$-N-dimethylformamide to yield the proton bound dimer of N-N-dimethylformamide at $\mathrm{m} / \mathrm{z} 147$ (with an apparent bimolecular association rate constant of $1.7 \times 10^{-10} \mathrm{~cm}^{3} \cdot \mathrm{molec}^{-1} \cdot \mathrm{s}^{-1}$, see Figure 6). In the case of protonated pyrrole $\left(\mathrm{PA}=209.2 \mathrm{kcal} \cdot \mathrm{mol}^{-1}\right.$ ) with camphene $\left(\mathrm{PA} \sim 210 \pm 2 \mathrm{kcal} \cdot \mathrm{mol}^{-1}\right.$ ) or protonated camphene with pyrrole, an association product ion at $\mathrm{m} / \mathrm{z}$ 204 was observed (data not shown). Other minor and/or slow reaction channels of the terpene ions with their parent neutrals are insignificant for constructing our predictive SCI model for short delay times (e.g., $<10 \mathrm{~s}$ after the ionization event, see Figure 7); however, the minor/ slow reaction channels can be incorporated to our model (discussed in the modeling section below) and predict SCI mass spectral patterns at longer reaction delay times.

\section{Terpene SCI Simulation Model and Comparison with Experimental Results}

SCI experiments. A series of $\alpha$-pinene and camphene SCI mass spectra using two static reaction pressures of $3.5 \times 10^{-8}$ and $7.0 \times 10^{-8}$ torr (ion gauge readings) were acquired at variable reaction delays $(20 \mathrm{~ms}$ to $200 \mathrm{~s}$ immediately following the $10 \mathrm{~ms}$ EI event). Figure 7 shows the $\mathrm{m} / z 137$ to $m / z 136$ ratio $\left(\mathrm{RA}_{\mathrm{SCI}}\right)$ as a function of reaction delay time ( $0-10 \mathrm{~s}$ only) for SCI mass spectra acquired at a pressure of $3.5 \times 10^{-8}$ torr for both $\alpha$-pinene $(\diamond)$ and camphene $(\bigcirc)$. Also, shown in Figure 7 are the SCI modeling results (--- for $\alpha$-pinene and for camphene).

Experimental results showed that the camphene system was more reactive than $\alpha$-pinene ensemble toward SCI; this is consistent with our previous GC/FT-ICR MS results on SCI based differentiation of $\alpha$-pinene and camphene [1]. At short reaction delays $(t<15 \mathrm{~s})$, the $\alpha$-pinene SCI mass spectra showed higher abundance of association ion-molecule product ions (at $\mathrm{m} / \mathrm{z} 217$ and 273) than camphene. On the other hand, the camphene SCI mass spectra showed major SCI ions at $m / z 81$ and 137; the association product ions at $\mathrm{m} / z 217 \mathrm{(m} / \mathrm{z} 81$ with camphene) and $\mathrm{m} / \mathrm{z} 273(\mathrm{~m} / \mathrm{z} 137$ with camphene) appeared at longer reaction delay times $(t>50 \mathrm{~s})$.

SCI modeling procedure. A one-step (Scheme 1, eq 4) and a two-step (Scheme 2, eq 5 for the formation of the intermediate product ions such as $\mathrm{m} / \mathrm{z} 94$ from camphene $\mathrm{m} / \mathrm{z}$ 136) type pseudo first-order irreversible exponential decay kinetic schemes were used to calculate the low mass resolution $\mathrm{m} / \mathrm{z} 137$ to $\mathrm{m} / \mathrm{z} 136$ ratio $\left(\mathrm{RA}_{\mathrm{SCI}}\right.$, eq 10). Calculations were carried out for the parent (M) and fragment ion (F) populations to model $\mathrm{SCI}$ as a function of pressure $(\mathrm{P})$ and ion-molecule reaction delay time (t). The modeling was performed using Microsoft Excel (Microsoft Office 2003).

To reduce the computational complexity, we classified the peaks in the mass spectrum into two main categories, viz. all observed fragment ions as one fragment ion fraction $(\mathrm{F})$ and the molecular ion fraction $(\mathrm{M})$ as the other category. The values for $F_{0}\left(\sum f_{i}\right.$ at $t=20 \mathrm{~ms}$ where $f_{i}$ is the abundance of each fragment ion peak $\left\{\mathrm{f}_{\mathrm{i}}^{\prime+}\right\}$ where the $" \cdot /+{ }^{\prime \prime}$ superscript denotes both potential odd and even electron fragment ions) and $\mathbf{M}_{0}(\mathrm{~m} / \mathrm{z}$ 136 abundance) were assigned from the FT-ICR mass spectral peak abundances (detected $20 \mathrm{~ms}$ after the 10 $\mathrm{ms} 24 \mathrm{eV}$ EI event). The total of these two ion population fractions makes up 100\% of the observed ions (i.e., $\mathrm{F}_{0}+\mathrm{M}_{0}=1.0$ normalization).

Scheme 3 shows reaction networks for ionized $\alpha$-pinene and camphene at $24 \mathrm{eV}$. The summed fragment ion population ensemble $\left(\Sigma \mathrm{f}_{\mathrm{i}}^{+}\right)$of $\alpha$-pinene $(\sim 91 \%)$ and camphene $(\sim 92 \%)$ have either three or two reaction channels, respectively. Namely, a PT channel (branching ratio $\mathrm{R}_{\mathrm{PT}}$, both $\alpha$-pinene $\{\sim 55 \%\}$ and camphene $\{\sim 80 \%\})$ to give protonated terpenes at $\mathrm{m} / \mathrm{z} 137$ ( $\mathrm{I}_{\mathrm{PT} 137}\{\mathrm{t}\}$, eq 4), a CT channel (total branching ratio $\mathrm{R}_{\mathrm{CT}}$, $\alpha$-pinene only $\{\sim 15 \%\})$ to yield terpene molecular ions (at $m / z$ 136, $\mathrm{I}_{\mathrm{CT} 136}\{\mathrm{t}\}$, eq $7,\{\sim 13 \%\}$ and $137, \mathrm{I}_{\mathrm{CT} 136}\{\mathrm{t}\}$, $\{\sim 2 \%\})$, and an unreactive component (branching ratio $\left\{1-\mathrm{R}_{\mathrm{PT}}-\mathrm{R}_{\mathrm{CT}}\right\}$, both $\alpha$-pinene $\{\sim 30 \%\}$ and camphene $\{\sim 20 \%\})$. It should be noted that the $\alpha$-pinene molecular ions charge exchanging with $\alpha$-pinene neutrals do not alter the $\mathrm{m} / \mathrm{z} 137$ to $\mathrm{m} / \mathrm{z} 136$ abundance ratio. Conversely, camphene ions at $\mathrm{m} / \mathrm{z} 136$ (from a total of $\sim 8 \%$ ) are either unreactive $\left\{32 \%\right.$ or $\left.R_{U R} \sim 0.32\right\}$ or form protonated camphene $\{\sim 68 \%\}$ via intermediate species
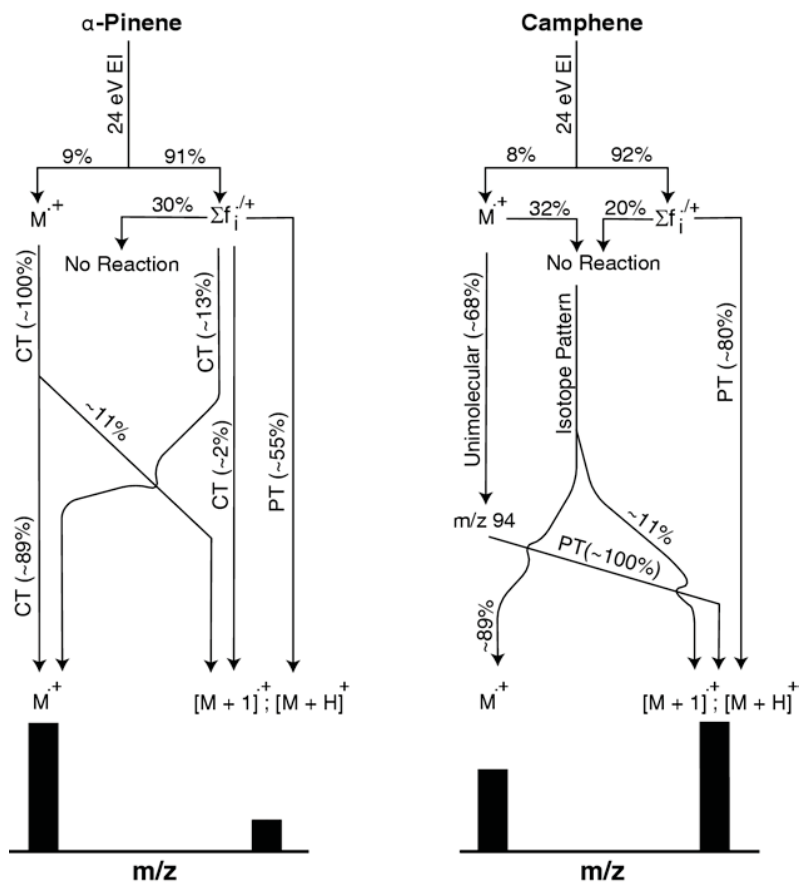

Scheme 3. Reaction networks for $\alpha$-pinene and camphene. 
Table 2. List of experimental values and kinetic parameters used to model SCI

\begin{tabular}{|c|c|c|c|c|}
\hline Parameter & Units & Camphene & $\alpha$-Pinene & Parameter description or comments ${ }^{a}$ \\
\hline $\mathrm{F}_{0}$ & - & 0.92 & 0.91 & $\Sigma$ of all fragment ion abundances $(\Sigma$ of all MS peaks $=1)$ \\
\hline $\mathrm{k}_{\mathrm{CT}}$ & $\mathrm{cm}^{3} \cdot \mathrm{molec}^{-1} \cdot \mathrm{s}^{-1}$ & - & $2.0 \times 10^{-9}$ & $\begin{array}{l}\text { Phenomenological charge transfer }(\mathrm{CT}) \text { rate constant }(\mathrm{RC}) \text { for } \\
\Sigma \text { fragment ions }\end{array}$ \\
\hline $\mathrm{k}_{\mathrm{PT}}$ & $\mathrm{cm}^{3} \cdot \mathrm{molec}^{-1} \cdot \mathrm{s}^{-1}$ & $5.7 \times 10^{-10}$ & $2.8 \times 10^{-10}$ & Phenomenological proton transfer (PT) RC for $\Sigma$ fragment ions \\
\hline $\mathrm{k}_{\text {PT94 }}$ & $\mathrm{cm}^{3} \cdot \mathrm{molec}^{-1} \cdot \mathrm{s}^{-1}$ & $1.4 \times 10^{-9}$ & - & Phenomenological PTRC for 92, 94, and 121 fragment ions $^{\mathrm{b}}$ \\
\hline $\mathrm{M}_{0}$ & - & 0.08 & 0.09 & Molecular ion abundance $(\Sigma$ of all MS peaks $=1)$ \\
\hline $\mathrm{P}$ & torr & $3.5 \times 10^{-8}$ & $3.5 \times 10^{-8}$ & lon gauge pressure reading (uncorrected for CS and gf) \\
\hline $\mathrm{R}_{\mathrm{CT}}$ & - & 0.0 & 0.15 & CT branching ratio of $\Sigma$ fragment ions \\
\hline$R_{\mathrm{PT}}$ & - & 0.80 & 0.55 & PT branching ratio of $\Sigma$ fragment ions \\
\hline $\mathrm{R}_{\text {PT94 }}$ & - & 1.0 & - & PT branching ratio of 92,94 , and 121 fragment ions ${ }^{\mathrm{b}}$ \\
\hline $\mathrm{R}_{\mathrm{u} 136}$ & - & 0.68 & 0.0 & Unimolecular dissociation branching ratio of $\mathrm{M}^{++}$ \\
\hline$\tau_{\mathrm{CT}}$ & s & - & 2.2 & Phenomenological CT time constant for $\Sigma$ fragment ions \\
\hline$\tau_{\mathrm{PT}}$ & s & 7.7 & 15.5 & Phenomenological PT time constant for $\Sigma$ fragment ions \\
\hline$\tau_{\mathrm{u} 136}$ & s & 20 & - & Molecular ion unimolecular dissociation time constant \\
\hline
\end{tabular}

${ }^{a}$ The values for $\mathrm{M}_{0}, \mathrm{~F}_{0}$, and the various $\mathrm{SCl}$ simulation reaction channel branching ratios listed in Table 2 refer to a time $\sim 20 \mathrm{~ms}$ after the $10 \mathrm{~ms} 24$ $\mathrm{eV}$ El event (i.e., a reaction delay time $=0 \mathrm{~s}$ in the $\mathrm{SCl}$ simulation calculations).

${ }^{\mathrm{b}}$ Fragment ions at $\mathrm{m} / \mathrm{z} 92,94$, and 121 refer to unimolecular dissociation products from camphene molecular ions at $\mathrm{m} / \mathrm{z} 136$ (ions at $\mathrm{m} / \mathrm{z} 94 \mathrm{were}$ the major intermediate product ions).

at $m / z 94$ \{major channel\} and $m / z 92$ and 121 \{minor channels\}). The kinetic results obtained on the study of the ion-molecule reactions of $\mathrm{m} / \mathrm{z}$ 93, 94 (Reaction 4, Table 1) and $m / z 121$ were used as a guide to assign reasonable initial phenomenological values to the branching ratios $\mathrm{R}_{\mathrm{PT}}$ and $\mathrm{R}_{\mathrm{CT}}$, the proton transfer $\left(\mathrm{k}_{\mathrm{PT}}\right)$ and charge-transfer $\left(\mathrm{k}_{\mathrm{CT}}\right)$ rate constants. An iterative process was used to vary the initial input values to improve the match between the experimental results and model predictions. The best fit values for all kinetic parameters obtained in our modeling are shown in Table 2 and are in general agreement with the experimental results shown in Table 1.

The MS Excel calculations (eqs 4-10) were formulated in terms of reaction time constants as input (e.g., $\tau_{x}$ in eqs $4-7)$. The pseudo first-order time constants for proton $\left(\tau_{\mathrm{PT}}\right)$ and charge-transfer $\left(\tau_{\mathrm{CT}}\right)$ reactions were calculated at a specified terpene pressure reading using eq 3 . The appropriate chemical sensitivity (9.0 for both $\alpha$-pinene and camphene) and pressure geometry $(\mathrm{g}=0.55)$ factors were used to correct the experimental value for the pressure before using it in the model. Equations 4-9 were used to calculate contributions to $\mathrm{m} / \mathrm{z} 136$ and 137 from $\mathrm{F}$ (i.e., $\Sigma$ fragment ions) and $\mathrm{M}$ (i.e., molecular cations) population fractions. For example, the yield of $\mathrm{m} / \mathrm{z} 136$ from the fragment ions was calculated using eq 7. The molecular ions of $\alpha$-pinene do not yield significant amount of SCI product ion $[\mathrm{M}+\mathrm{H}]^{+}$at $m / z=137$. It was observed that the molecular ions of camphene produced SCI product ions only via intermediate reaction channels (e.g., $136^{+^{*}} \rightarrow 94^{+} \rightarrow 137^{+}$).

The camphene molecular ion has a unimolecular reaction channel $\left(R_{\mathrm{u} 136}=0.68\right)$ with a time constant $\left(\tau_{\mathrm{u} 136}=20 \mathrm{~s}\right)$ to yield $\mathrm{m} / \mathrm{z} 94$ as the major product ion. The EI produced terpene molecular ion abundance is given by eq 6 . The unimolecular product ions at $m / z 92$, 94 , and 121 reacted with camphene at a phenomenological rate of $1.4 \times 10^{-9} \mathrm{~cm}^{3} \cdot \operatorname{molec}^{-1} \cdot \mathrm{s}^{-1}$ to give protonated camphene at $\mathrm{m} / \mathrm{z} 137$. The yield of ions at $m / z$ 92, 94, and 121 (denoted as $\mathrm{I}_{94}\{t\}$ since 94 is the major intermediate product ion), is calculated using eq 5 [27]. The total yield of $m / z 137$ was calculated using eq 9 that includes the ${ }^{13} \mathrm{C}_{1}$ isotopomer contribution from $\mathrm{m} / \mathrm{z} 136$ (0.11 abundance of $\mathrm{m} / \mathrm{z} 136)$. The term $\left(\mathrm{M}_{0}-\right.$ $\left.I_{\text {u136 }}\{t\}-I_{94}\{t\}\right)$ in eq 9 is the yield of $m / z 137$ produced from $m / z 136$ of camphene or $\alpha$-pinene $\left(\boldsymbol{R}_{\mathrm{u}}\right.$ and $\tau_{\mathrm{u} 136}$ for $\alpha$-pinene are near zero and infinity, respectively). The terms $I_{\text {total136 }}(t)$ and $I_{94}(t)$ represent the relative abundances of $\mathrm{m} / \mathrm{z} 136$ and $\mathrm{m} / \mathrm{z}$ 94, respectively. A summary of the values for all parameters used in the $\mathrm{RA}_{\mathrm{SCI}}$ calculation is provided in Table 2.

$$
\begin{aligned}
& \mathrm{I}_{\mathrm{PT} 137}(\mathrm{t})=\mathrm{R}_{\mathrm{PT}} \times \mathrm{F}_{0} \times\left(1-\exp \left(-\mathrm{t} / \tau_{\mathrm{PT}}\right)\right) \\
& \mathrm{I}_{94}(\mathrm{t})=\mathrm{R}_{\mathrm{u} 94} \times \mathrm{M}_{0} \times\left(\exp \left(-\mathrm{t} / \tau_{\mathrm{u} 94}\right)\right. \\
& \left.-\left(\exp \left(-\mathrm{t} / \tau_{\mathrm{PT} 94}\right)\right) \times \tau_{\mathrm{PT} 94}\right) /\left(\tau_{\mathrm{u} 94}-\tau_{\mathrm{PT} 94}\right)
\end{aligned}
$$

Abundance of the EI produced $\mathrm{M}^{+}(\mathrm{m} / \mathrm{z} 136$, eq 6) at any time $\left(\mathrm{I}_{136}\{\mathrm{t}\}\right)$ is a combination of the unreactive fraction of $\mathrm{M}^{+}$plus the surviving $\mathrm{M}^{++*}$ (i.e., ions that have not undergone unimolecular dissociation).

$$
\begin{aligned}
& \mathrm{I}_{\mathrm{u} 136}(\mathrm{t})=\left(\left(1-\mathrm{R}_{\mathrm{u} 136}\right) \times \mathrm{M}_{0}\right)+\left(\mathrm{R}_{\mathrm{u} 136} \times \mathrm{M}_{0}\right. \\
& \left.\times \exp \left(-\mathrm{t} / \tau_{\mathrm{u} 136}\right)\right)
\end{aligned}
$$

However, ions at $m / z 136$ are also produced by charge-transfer from the fragment ions; eq 7 can be used to calculate the number of ions produced by chargetransfer $\left(\mathrm{I}_{\mathrm{CT} 136}\{\mathrm{t}\}\right)$ at any time:

$$
\mathrm{I}_{\mathrm{CT} 136}(\mathrm{t})=\mathrm{R}_{\mathrm{CT}} \times \mathrm{F}_{0} \times\left(1-\exp \left(-\mathrm{t} / \tau_{\mathrm{CT}}\right)\right)
$$

To calculate the total abundance of ions at $\mathrm{m} / \mathrm{z} 136$ $\left(I_{\text {total136 }}\{t\}\right)$, contributions from eqs 6 and 7 can be added:

$$
\mathrm{I}_{\text {total136 }}(\mathrm{t})=\mathrm{I}_{\mathrm{u} 136}(\mathrm{t})+\mathrm{I}_{\mathrm{CT} 136}(\mathrm{t})
$$


This summed value of $\mathrm{I}_{\text {total136 }}(\mathrm{t})$ along with proton transfer reaction contributions can be use to calculate the abundance of $m / z 137\left(\mathrm{I}_{\text {total137 }}\{\mathrm{t}\}\right)$ :

$$
\begin{aligned}
& \mathrm{I}_{\text {total137 }}(\mathrm{t})=\left(0.11 \times \mathrm{I}_{\text {total136 }}(\mathrm{t})\right)+\left(\mathrm{I}_{\mathrm{PT} 137}(\mathrm{t})\right) \\
& +\left(\mathrm{M}_{0}-\mathrm{I}_{\mathrm{u} 136}(\mathrm{t})-\mathrm{I}_{94}(\mathrm{t})\right)
\end{aligned}
$$

Finally, the $m / z$ 137:136 ratio $\left(\mathrm{RA}_{\mathrm{SCI}}\right)$ can be calculated be dividing eq 9 by eq 8 :

$$
\operatorname{RA}_{\mathrm{SC} 1}(\mathrm{t})=\mathrm{I}_{\text {total137 }}(\mathrm{t}) / \mathrm{I}_{\text {total136 }}(\mathrm{t})
$$

Comparison of experiment with SCI modeling. The ion gauge pressure reading of $3.5 \times 10^{-8}$ torr was corrected for chemical sensitivity and the instrument geometry factor to construct the modeling plots shown in Figure 7. Both experiment $(\diamond, \bullet)$ and modeling $(--,-)$ clearly show that $\alpha$-pinene undergoes SCI less readily than camphene as monitored by $\mathrm{RA}_{\mathrm{SCI}}(\mathrm{t})$. Additional set of experimental data at experimental camphene and $\alpha$-pinene pressure of $7.0 \times 10^{-8}$ torr confirmed the validity of the SCI model (data not shown in Figure 7). Our model did not include relatively minor contributions from condensation, hydride abstraction, association, and other ion-molecule reaction channels that may alter marginally the $\mathrm{m} / \mathrm{z} 136$ and $\mathrm{m} / \mathrm{z} 137$ abundances for reaction delays less than $\sim 15 \mathrm{~s}$. Terpene pressure in the ICR cell and reaction delay time of $\sim 4 \mathrm{~s}$ from our previous GC/FT-ICR MS ${ }^{1}$ work are within the applicable range of the current model. At longer reaction delays $(>\sim 15 \mathrm{~s})$, the SCI model used here predicted smaller camphene $\mathrm{RA}_{\mathrm{SCI}}$ values compared with the experimental data; this underlines the importance of minor and/or slow reaction channels at longer reaction delays.

\section{Conclusions}

Based on the kinetic results presented in this paper, a simple model was constructed to predict SCI mass spectral patterns for $\alpha$-pinene and camphene molecular ion region as a function of reaction delay time and analyte pressure.

Neither $\alpha$-pinene nor camphene molecular ions yielded SCI products directly. Camphene unimolecular dissociation produced intermediate ions (e.g., at $\mathrm{m} / \mathrm{z}$ 94), which subsequently protonated neutral camphene; however, these reaction channels represented only a small fraction of the observed SCI product at $\mathrm{m} / \mathrm{z} 137$. The $\alpha$-pinene molecular cation was inert toward SCI. Terpene fragment ion reactions were the main factors determining the SCI mass spectral patterns for $\mathrm{M}$ and $\mathrm{M}+1$ regions of both $\alpha$-pinene and camphene terpenes.

Thermalized $m$-xylene molecular ions $(\mathrm{IE}=8.55 \mathrm{eV})$ charge transferred to camphene efficiently $(\mathrm{k}=1.2 \times$ $\left.10^{-9} \mathrm{~cm}^{3} \cdot \mathrm{molec}^{-1} \cdot \mathrm{s}^{-1}\right)$, implying a camphene ionization energy of $<8.55 \mathrm{eV}$. This IE value for camphene is lower than the upper limit of $8.86 \mathrm{eV}$ reported and closer to $\alpha$-pinene's reported IE $=8.07 \mathrm{eV}$ [29]. Moreover, the PES ionization threshold of $\sim 8.0 \mathrm{eV}$ for camphene [6] qualitatively agrees with our $m$-xylene charge-transfer data as well as ionization and appearance energy measurements on camphene.

The proton affinities of camphene and $\alpha$-pinene are comparable. Based on our experimental results, the proton affinities of camphene and $\alpha$-pinene are conservatively estimated to be within the range $\sim 210 \pm 2 \mathrm{kcal}$ - $\mathrm{mol}^{-1}$. Future work focusing on using the thermokinetic method of Bouchoux [37] and FT-ICR equilibrium proton transfer experiments combined with $a b$ initio calculations may provide more accurate PA values.

\section{Acknowledgments}

This material is based upon work supported by the National Science Foundation under grant no. CHE-0228971.

\section{References}

1. Solouki, T.; Szulejko, J. E.; Bennett, J. B.; Graham, L. B. A Preconcentrator Coupled to a GC/FTMS: Advantages of Self-Chemical Ionization, Mass Measurement Accuracy and High Mass Resolving Power for GC Applications. J. Am. Soc. Mass Spectrom. 2004, 15, 1191-1200.

2. Vincenti, M.; Horning, S. R.; Cooks, R. G. Energetics of Retro-Diels-Alder Fragmentation in Limonene as Characterized by Surface-Induced Dissociation, and Energy- and Angle-Resolved Mass Spectrometry. Org. Mass Spectrom. 1988, 23, 585-593.

3. Gilchrist, T.; Reed, R. I. Electron-Induced Dissociation of some Monoterpenoids. Experientia 1960, 16, 134-135.

4. Brophy, J. J.; McColl, A. Low-Energy, Low-Temperature Mass Spectra. Part 15. Electron Ionization Mass Spectra of Some Monoterpenes Hydrocarbons. Org. Mass Spectrom. 1992, 27, 1042-1051.

5. Garcia, G. A.; Nahon, L.; Powis, I. Near-Threshold Photoionization Spectroscopy of Monoterpenes Limonene and Carvone. Int. J. Mass Spectrom. 2003, 225, 261-270.

6. Novak, I.; Ng, S. C.; Kovac, B. He I Photoelectron Spectra of Some Camphor Derivatives. Spectrochim. Acta 1993, 49A, 1629-1631.

7. Novak, I.; Kovac, B. Photoelectron Spectroscopy of Natural Products: Terpenes. Spectrochim. Acta A 2005, 61A, 277-280.

8. Beckey, H. D.; Hey, H. Combination of Field Ionization and Electron Impact Mass Spectra for Structural Determination, Particularly Monoterpene Structures. Org. Mass Spectrom. 1968, 1, 47-60.

9. Schwarz, H.; Borchers, F.; Levsen, K. Stoßaktivierungsmassenspektromerie von Monoterperen und Isomerisierung von $\mathrm{C}_{7} \mathrm{H}_{9}{ }^{+}$-Ionen in der Gasphase. Zeitschrift Naturforsch. B: Chem. Sci., 1976, 31B, 935-940.

10. Friedman, L.; Wolf, A. P. Electron Impact Dissociation of Camphene-8$\mathrm{C}^{13}$. J. Am. Chem. Soc. 1958, 80, 2424-2426.

11. Harris, D.; McKinnon, S.; Boyd, R. K. The Origins of the Base Peak in the Electron Impact Spectrum of Limonene. Org. Mass Spectrom. 1979, 14 , 265-272.

12. Ryhage, R.; Sydow, E. V. Mass Spectrometry of Terpenes I Monoterpene Hydrocarbons Acta Chem. Scand. 1963, 17, 2025-2035.

13. Hill, H. C.; Reed, R. I.; Robert-Lopes, M. T. Mass Spectra and Molecular Structure. Part I. Correlation Studies and Metastable Transitions. J. Chem. Soc. C 1968, 93-101.

14. Basic, C.; Harrison, A. G. A Mass Spectral Study of Some $\mathrm{C}_{10} \mathrm{H}_{16}$ Monoterpenes. Can. J. Appl. Spectrosc. 1991, 36, 33-40.

15. Thomas, A. F.; Willhalm, B. Les Spectres de Masse des Hydrocarbures Monterpeniques. Helv. Chim. Acta 1964, 47, 475-488.

16. de Gouw, J.; Warneke, C.; Karl, T.; Eerdekens, G.; van der Veen, C.; Fall, R. Sensitivity and Specificity of Atmospheric Trace Gas Detection by Proton-Transfer-Reaction Mass Spectrometry. Int. J. Mass Spectrom. 2003, 223-224, 365-382

17. Wang, T.; Spanel, P.; Smith, D. Selected Ion Flow Tube, SIFT, Studies of the Reactions of $\mathrm{H}_{3} \mathrm{O}^{+}, \mathrm{NO}^{+}$, and $\mathrm{O}_{2}^{+}$with Eleven $\mathrm{C}_{10} \mathrm{H}_{16}$ Monoterpenes. Int. J. Mass Spectrom. 2003, 228, 117-126.

18. Chan, K. K. Quantification of Monoterpenoid Compounds with Potential Medicinal Use in Biological Fluids. J. Chromatogr. A 2001, 936, 47-57.

19. Solouki, T.; Fort, R.; Alomary, A.; Fattahi, A. Gas-Phase Hydrogen Deuterium Exchange Reactions of a Model Peptide: FT-ICR and Computational Analyses of Metal Induced Conformational Mutations. J. Am. Soc. Mass Spectrom. 2001, 12, 1272-1285.

20. Wang, T.-C. L.; Ricca, T. L.; Marshall, A. G. Extension of Dynamic Range in Fourier Transform Ion Cyclotron Resonance Mass Spectrometry via Stored Waveform Inverse Fourier Transform Excitation. Anal. Chem. 1986, 58, 2935-2938. 
21. Jiao, C. Q.; Ranatunga, D. R. A.; Vaughn, W. E.; Freiser, B. S. A Pulsed-Leak Valve for Use with Ion Trapping Mass Spectrometers. J. Am. Soc. Mass Spectrom. 1996, 7, 118-122.

22. Bartmess, J. E.; Georgiadis, R. M. Empirical Methods for Determination of Ionization Gauge Relative Sensitivities for Different Gases. Vacuum 1983, 33, 149-153.

23. Nakao, F. Determination of the Ionization Gauge Sensitivities Using the Relative Ionization Cross-Section. Vacuum 1975, 25, 431-435.

24. Miller, K. J.; Savchik, J. A. A New Empirical Method to Calculate Average Molecular Polarizabilities. J. Am. Chem. Soc. 1979, 101, 72067213.

25. CRC Handbook of Chemistry and Physics, 77th ed.; Lide, D. R.; Frederikse, H. P. R., Eds.; CRC Press Inc.: Baton Rouge, LA, 1996/1997; pp 10-210.

26. Anicich, V. Ion-Molecule Reaction Kinetics Database on CD; Jet Propulsion Laboratory (JPL) Databases: 2003.

27. Steinfeld, J. I.; Francisco, J. S.; Hase, W. L. Chemical Kinetics and Dynamics; Prentice Hall: Englewood Cliffs, NJ, 1989; p 27.

28. Johnstone, R. A. W. In Mass Spectrometry, Volume 5: Specialist Periodical Reports; Johnstone, R. A. W., Ed.; The Chemical Society: Bristol, 1979; p. 38 .

29. NIST Chemistry WebBook; NIST Standard Reference Database 69, http:// webbook.nist.gov/chemistry/

30. Salpin, J. Y.; Mormann, M.; Tortajada, J.; Nguyen, M. T.; Kuck, D. The Gas-phase Basicity and Proton Affinity of 1,3,5-Cycloheptatriene-
Energetics, Structure, and Interconversion of Dihydrotropylium Ions. Eur. J. Mass Spectrom. 2003, 9, 361-376.

31. Szulejko, J. E.; Hrušák, J.; McMahon, T. B. Combined Experimental and Theoretical Study of the Protonation of Polyfluorobenzenes $\left[\mathrm{C}_{6} \mathrm{H}_{6-n} \mathrm{~F}_{n}\right]$ $\mathrm{n}=0-6$. J. Mass Spectrom. 1997, 32, 494-506.

32. Aubry, C. Holmes, J. L. Correlating Thermochemical Data for Gasphase Ion Chemistry. Int. J. Mass Spectrom. 2000, 200, 277-284.

33. Ebmeyer, F. Theoretical Investigations Towards an Understanding of the $\alpha$-Pinene/Camphene Rearrangement. J. Mol. Struct. (Theochem.) 2002, 582, 251-255

34. Szulejko, J. E.; McMahon, T. B. Progress Toward an Absolute Gas-Phase Proton Affinity Scale. J. Am. Chem. Soc. 1993, 115, 7839-7848.

35. Drummond, D. F.; McMahon, T. B. Additivity of Fluorine Substituent Effects in the Gas-Phase Basicities of Fluorinated Acetones. J. Phys. Chem. 1981, 85, 3746-3748.

36. Smith, B. J.; Radom, L. An Evaluation of the Performance of Density Functional Theory, MP2, MP4, F4, G2(MP2), and G2 Procedures in Predicting Gas-Phase Proton Affinities. Chem. Phys. Lett. 1994, 231, 345-351.

37. Bouchoux, G.; Salpin, J. Y.; Leblanc, D. A Relationship between the Kinetics and Thermochemistry of Proton Transfer Reactions in the Gas Phase. Int. I. Mass Spectrom. Ion Processes 1996, 153, 37-48.

38. Nibbering, N. M. M. The Role of Mass Spectrometric Methods in Ionic Reaction Mechanistic Studies. Int. J. Mass Spectrom. 2000, 200, 27-42. 